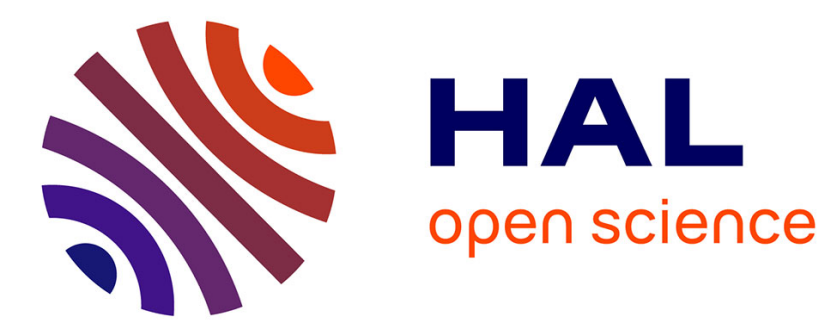

\title{
Word-final consonant epenthesis in Northeastern Nigerian English
}

\author{
Dmitry Idiatov
}

\section{To cite this version:}

Dmitry Idiatov. Word-final consonant epenthesis in Northeastern Nigerian English. English Language and Linguistics, 2017, 23 (2), pp.303-340. 10.1017/S1360674317000429 . halshs-01676384

\section{HAL Id: halshs-01676384 \\ https://shs.hal.science/halshs-01676384}

Submitted on 5 Jan 2018

HAL is a multi-disciplinary open access archive for the deposit and dissemination of scientific research documents, whether they are published or not. The documents may come from teaching and research institutions in France or abroad, or from public or private research centers.
L'archive ouverte pluridisciplinaire HAL, est destinée au dépôt et à la diffusion de documents scientifiques de niveau recherche, publiés ou non, émanant des établissements d'enseignement et de recherche français ou étrangers, des laboratoires publics ou privés. 


\title{
Word-final consonant epenthesis in North-eastern Nigerian English ${ }^{1}$
}

\author{
DMITRY IDIATOV \\ LLACAN (CNRS - USPC/INALCO)
}

\footnotetext{
${ }^{1}$ The present paper results from a joint project with Mark Van de Velde on the description of Bena. Our main Bena consultants come from the village of Dumne, Adamawa State (N 9 $47^{\prime}$ E 12 $23^{\prime}$ ). This work is situated within the projects AdaGram (program "Émergence(s)" of the City of Paris) and LC2 "Areal phenomena in Northern sub-Saharan Africa" of the Labex EFL (program "Investissements d'Avenir" overseen by the French National Research Agency, reference: ANR-10-LABX-0083). Special thanks with respect to the present paper are due to Mark Van de Velde and Yuni Kim. I am also very grateful for feedback and comments from the editor Patrick Honeybone and the anonymous reviewers.
} 


\begin{abstract}
L2 speakers of Nigerian English in parts of north-eastern Nigeria occasionally insert an alveolar coronal stop [t] or fricative [s] following another alveolar coronal pre-pausally and phraseinternally. The paper discusses this typologically unusual phenomenon for the Nigerian English of speakers whose L1 is the Adamawa language Bena (ISO 639-3: yun). I also consider comparable cases of word-final consonant epenthesis in several other varieties of English, both the so-called New Englishes and Inner Circle varieties, and provide an account of the details of epenthesis with respect to which they differ. At first sight, hypercorrection of the tendency for word-final consonant cluster simplification in Bena English may seem an obvious explanation. However, I argue that hypercorrection alone falls short of explaining the observed pattern. In addition, we need to call on phonetic properties of Bena L1 such as pre-pausal glottalisation and lengthening of consonants to be able to account for both the actuation of the hypercorrection and the phonologisation of the epenthesis. Although the availability of a clear phonetic explanation makes this sound pattern conceivable as a natural rule, its typological rarity in non-contact lects highlights the positive bias induced by hypercorrection as a necessary part of the mix in creating the conditions for a reanalysis.
\end{abstract}

Keywords: Nigerian English, New Englishes, Inner Circle Englishes, Bena, word-final consonant epenthesis, hypercorrection, consonant cluster simplification 


\section{INTRODUCTION}

L2 speakers of Nigerian English (NE) in parts of north-eastern Nigeria occasionally produce a non-etymological coronal stop [t] or fricative [s] following a word-final coronal pre-pausally, as in (1), and phrase-internally, as in (2). ${ }^{2}$

\section{(1) pre-pausal}

(a) How is Paris[t]?

(b) Control-X [-ikst]

(c) I need to get a bus[t]

(d) He did it because $[\mathrm{t}] \mid \ldots$

(e) (It) is cool[t]

(f) I want to use three days[t]

(g) So the girl spen(t) $\mid$ one night $[\mathrm{s}] \mid \ldots$

(h) By the morning $\mid$ the husban(d) left[s]

(i) If the hole is sealed by the soil[s] $\mid \ldots$

(2) phrase-internal

(a) This[t] year

(b) So my original plan[t] is that...

(c) She don('t) have $\mid$ even[s] a spot on her body

(d) And the girl[ $\left.\mathbf{s}^{\circ}\right]$ realised that this is the man, that she know(s) him

The paper discusses this typologically unusual phenomenon for Bena English (BE), that is the English of speakers whose L1 is Bena (ISO 639-3:yun; cf. Map 1), currently classified as Adamawa (Niger-Congo stock). Within NE, at least the production of a non-lexical [t] is not restricted to Bena L1 speakers. Thus, I heard examples of pre-pausal non-lexical [t] being produced by a man who is ethnically Bena, lives in the Bena community and can speak Bena but whose L1 is Hausa (ISO 639-3: hau; Chadic), an important regional language in northern Nigeria, as well as by three different people (two men and one woman) from Plateau State (cf. Map 1) who I encountered elsewhere in Nigeria. L1 of one of them is Mwaghavul (ISO 639-3: sur; Chadic), but I do not know L1 of the other two. For the moment, the wider geographic extent of

\footnotetext{
${ }^{2}$ Examples (1) and (2) illustrate the spontaneous English use of my consultants (cf. section 2), with examples (1a-d, 2a) coming from conversations with them and (1e-i, 2b-d) coming from recordings of their speech. The rounded brackets in the English examples mark parts omitted in the original.
} 
this phenomenon remains unknown. However, it is lacking in the varieties of Nigerian English from southern parts of Nigeria I have heard and it is not mentioned in the literature on Nigerian English, which focuses on southern Nigeria (cf. Simo Bobda 2007, Gut 2008, 2009a, 2009b, Ugorji 2010). Similarly, it has never been reported for Nigerian Pidgin English (Nicholas Faraclas, p.c.).

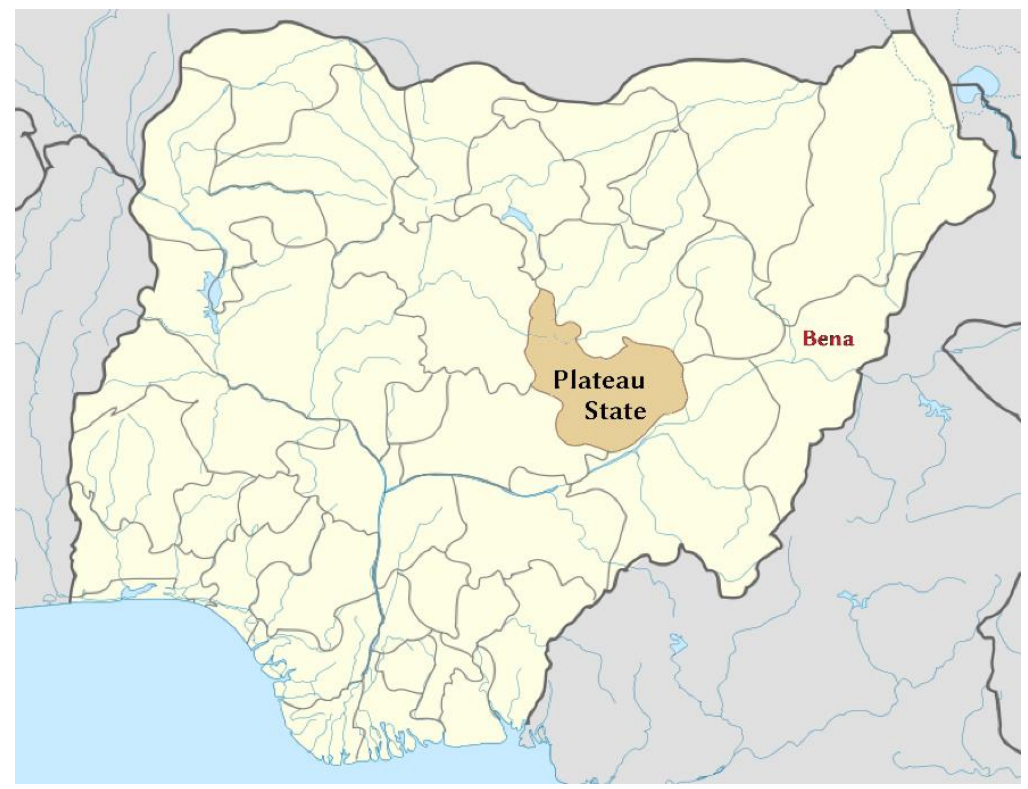

Map 1

The location of Bena and Plateau State in Nigeria

The productive realisation of non-etymological [t] or [s] following a word-final coronal prepausally and phrase-internally which I will refer to as word-final post-coronal $t$ or $s$ epenthesis or insertion, ${ }^{3}$ is typologically highly unusual (cf. Blevins 2007, Morley 2012, Ohala 2003: 681-2, Vaux 2002, Żygis 2010). ${ }^{4}$ I am aware of only one mention in the typological literature on consonant epenthesis in $\mathrm{L} 1$ of a process that is to a certain extent comparable to the BE epenthesis.

\footnotetext{
${ }^{3}$ One reviewer wondered about the use of the term productive in the paper. By productive rule I intend a rule that is not lexically restricted and can be applied to new items. As the rule is optional in this case, it does not need to apply in every environment where its conditions are met, but it could do in principle.

${ }^{4}$ While the productive excrescence of $[\mathrm{t}]$ and $[\mathrm{s}]$ in the relevant context is a typologically rare kind of change, the sporadic excrescence of at least [ $t$ ] may have happened in the Germanic languages somewhat more frequently than one would think. Thus, Minkova (2014:150) cites a dozen of examples of "the addition of a non-etymological <-t $>$ " in the history of English (see also section 7). One reviewer has also pointed out two cases from German, viz. Mond 'moon' and the pair niemand 'nobody' and jemand 'somebody'. The latter two words also show a non-etymological [t] in Dutch, viz. niemand and iemand.
} 
Thus, Morley (2012: 70) cites Broselow (1984) who analyses Amharic (Semitic; Ethiopia) "as inserting / $t$ / to satisfy templatic morphology; as a result, /t/ surfaces word-finally or as the second member of a two-consonant sequence". However, unlike in Amharic, the conditioning of the BE epenthesis is purely phonological and no comparable morphological explanation is possible with Bena L1.

Another important difference between BE and Amharic is of course that BE is an L2. The latter fact impels one to search for an explanation of the word-final post-coronal $t$ or $s$ epenthesis in BE by comparing the phonotactics of English as L2 and Bena as L1. It will not take one long to notice that unlike English, Bena does not have word-final consonant clusters (although consonant clusters are possible within words and across word boundaries) and that word-final consonant clusters are often simplified in BE. Thus, the $t$ or $s$ epenthesis in BE points towards an explanation in terms of phonological hypercorrection of the BE tendency for word-final consonant cluster simplification, which is itself due to the absence of word-final consonant clusters in Bena L1.

Indeed, hypercorrection of the BE tendency for word-final consonant cluster simplification is a very plausible historical source of the $t$ or $s$ epenthesis in BE. Another piece of evidence that highlights the role of hypercorrection in the emergence of the $\mathrm{BE}$ pattern is that $\mathrm{BE}$ is not the only variety of English that has been reported to occasionally insert a consonant at the end of a word after another consonant. Thus, comparable phenomena have been reported for a number of New Englishes in Southeast Asia, such as Singapore English, Hong Kong English (Setter \& Deterding 2003), and Brunei English (Deterding \& Sharbawi 2013: 29), and also in Central America, such as Miskito Coast Creole English (Holm 1988: 142), as well as for several of the so-called Inner Circle Englishes, such as older Southern rural white American English (Thomas 2008: 110) and Newfoundland English (Clarke 2008: 175). Importantly, all these varieties appear to have extensive word-final consonant cluster simplification largely irrespective of the phonological context to the right of the word in question, similarly to BE and unlike the varieties for which no such epenthesis has been reported, and the epenthetic consonant involved is also [t], and at least in one case also [s]. That is, like in BE, we observe a mismatch between the extensive word-final consonant cluster simplification in these varieties and the phonotactic pattern of major standard varieties of English (in their function as the prestige varieties) which has lots of such word-final clusters with $[\mathrm{t}]$ being the most common final consonant within these clusters. When explicitly analysed, the epenthesis in these varieties is always attributed to hypercorrection.

A hypercorrection analysis is good as a first approximation. However, a closer look at the data raises a number of important questions. To begin with, the details of epenthesis differ in 
different varieties of English in terms of the conditioning and especially productivity of the epenthesis. The Southeast Asian English varieties mentioned above come closest in resembling the BE pattern. Importantly, there are also varieties of English, such as the three major varieties of Nigerian English (viz. Yoruba, Igbo and Hausa NE) and Nigerian Pidgin English, that would have perfectly qualified for the emergence of word-final post-consonant $t$ epenthesis, if things were this simple. Thus, they also have extensive word-final cluster simplification, ${ }^{5}$ but have not been reported to show such kind of epenthesis. That is, extensive word-final cluster simplification is a necessary, but not sufficient condition for the development of word-final post-consonant $t$ epenthesis. Finally, that hypercorrection has played an important role in the emergence of a given pattern does not necessarily mean that a synchronic analysis of the pattern as hypercorrection is still adequate. In this respect, compare the conclusion that has been made by Childs \& Wolfram (2008: 249-250) regarding the "elusive" phonological status of the initial $h$ insertion in Bahamian English, where it co-exists with the much more frequent initial $h$ dropping and thus may seem like a type of hypercorrection. Thus, Childs \& Wolfram (2008: 249-250) convincingly argue that despite this difference in frequency, the two phenomena have an equal phonological status as "phonetic option[s] for word-initial vowels" and are both "traits of Bahamian English, showing both socially constrained and individually based variation”.

As we can see, labelling the word-final consonant epenthesis as hypercorrection falls short of answering many of the why and how questions and in fact may be inadequate from a synchronic point of view. Therefore, besides providing a description of the word-final post-coronal $t$ and $s$ epenthesis in BE, this paper pursues the following three major goals. First, the paper argues that although historically rooted in hypercorrection, a synchronic analysis of the word-final postcoronal $t$ and $s$ epenthesis in BE is inadequate. Second, I elaborate on the hypercorrection analysis of the emergence of the BE pattern by acknowledging the possibility that morphological hypercorrection has also contributed to the development of the $s$ epenthesis and by calling on phonetic properties of Bena L1 such as pre-pausal glottalisation and lengthening of consonants in order to provide a more plausible account for both the actuation of the hypercorrection and the phonologisation of the epenthesis. Third, I provide an overview of cases of word-final consonant epenthesis in other varieties of English and an account of the attested details of epenthesis with respect to which they differ from $\mathrm{BE}$ and from each other.

5 "In consonant clusters at the end of words, there is a tendency in many of the New Englishes not to pronounce the final consonant in a group of two [...] or the middle or final consonant in a group of three" (Platt, Weber \& Ho 1984: 43). 
The paper is organised as follows. I begin by presenting the nature of data discussed in the paper in section 2. I provide a brief overview of the consonant systems of BE as L2 in section 3 and Bena as L1 section 4. Section 5 provides a description of the word-final post-coronal $t$ and $s$ epenthesis in BE, including a description of the contexts where it occurs (5.1), relevant aspects of its phonetics (5.2) and a discussion of its synchronic phonological status (5.3). In section 6, I elaborate on the details of the hypercorrection scenario for the emergence of the BE pattern. Finally, in section 7, I discuss cases of word-final consonant epenthesis in other varieties of English, mentioned above, in comparison to the BE pattern and to each other.

\section{THE NATURE OF THE DATA}

The present description of BE is based primarily on my observations of spontaneous BE use made during my joint work on the description of Bena L1 together with Mark Van de Velde and complemented by a number of recordings where $\mathrm{BE}$ is used spontaneously but was not the primary object of the recording. Given the lack of a substantial and varied recorded spoken corpus of $\mathrm{BE}$ that would allow for a variationist type of analysis, I provide a more detailed account of the nature of the data discussed.

The data considered in this paper are the best data that are currently available and, due to ongoing security issues, the best data that are likely to be available for some time to come. The data were collected over a six month period of fieldwork on Bena in Nigeria. Because of the ongoing security issues in NE Nigeria, I have been able to work in the Bena community in situ in the village of Dumne for somewhat less than a month. During my stay in the community, I had the occasion to observe spontaneous BE use by dozens of speakers of different ages (ranging from teenagers to elders) and of different educational and professional backgrounds (ranging from secondary school students, farmers, university students to teachers, government officials and a former senator). Due to cultural restrictions, the speakers were almost all male. Therefore, we cannot exclude the possibility that the phenomenon is restricted to male speech. The situations of BE use were mostly natural conversations with Bena L1 speakers involving me and my colleague, some more formal events, as well as several dozens of hours of interview sessions whose subject was the description of Bena L1.

The remaining part of the fieldwork took place in SW Nigeria far from the Bena community with in total three different consultants, all males in their early 30s from the village of Dumne, all three having completed their secondary education and two of them also having spent some time at university. My colleague and I shared an apartment with the consultants which resulted 
in many hours of informal interaction with the consultants in English every day, in addition to the interview sessions on the description of Bena L1.

My colleague and I observed most speakers to produce occasional examples of pre-pausal $t$ epenthesis. We had the impression that in the speech of speakers with better overall English proficiency and university level education, pre-pausal $t$ epenthesis was less common, and for some such speakers possibly even absent altogether. Our three main consultants to whose BE speech I have been exposed for several months produced such examples on a daily basis. The one consultant who had no university level education experience was most prolific in this respect. At the same time, my attempts to elicit examples of the epenthesis with our three main consultants were not successful. Although, as I argue in section 5.3 there is a reasonable explanation for the problems I had with the elicitation, the existence of a sufficiently large and varied corpus of spontaneous BE speech would be needed to quantitatively substantiate my qualitative observations. Unfortunately, the Bena speaking area is currently inaccessible for security reasons.

Neither I nor my colleague had been aware of the pre-pausal $s$ epenthesis and the phraseinternal $t$ or $s$ epenthesis before I started searching our Bena recordings for examples of $t$ epenthesis in BE. That the phrase-internal $t$ and $s$ epenthesis remained unnoticed is likely to be due a combination of factors. First, it is rare, as I found only few examples in the recordings and I observed it directly in spontaneous speech only on one occasion (several repetitions of example (2a)). Second, its phrase-internal position may negatively affect its perceptual prominence, both because the consonants in this position have shorter duration, especially when compared to the position before pause, and because they run the risk of being masked by a following consonant. As to our lack of awareness of the $s$ epenthesis, both in the pre-pausal and the phrase-internal position, another factor is that it is too easy to filter out occurrences of an epenthetic [s] as morphological mistakes, for instance by assuming that plural $-S$ was used inappropriately, as is not uncommon in NE L2. For all these reasons, the discussion in the rest of the paper will be mostly confined to pre-pausal $t$ epenthesis.

My corpus of recordings contains 72 hours of interview sessions on the description of Bena L1. However, only a small part represents spontaneous BE use, for instance when the consultants volunteered an explanation in English. For the moment, I have been able to locate around 30 minutes of stretches of spontaneous BE use in these recordings which resulted in 14 cases of epenthesis: 10 before pause (6 for [t] and 4 for [s]) and 4 phrase-internally (1 for [t] and 3 for $[\mathrm{s}]$ ). Although in absolute terms these numbers are rather small, they suggest a relatively high rate of epenthesis, with one occurrence every 2-3 minutes of spontaneous speech. The number of 
non-recorded cases of at least pre-pausal $t$ epenthesis informally observed by my colleague and me is several times higher.

The examples of $t$ epenthesis in written BE come from a number of email exchanges with our Bena consultants and from a few pieces of written English that the consultants have produced on a number of occasions, such as writing down the English translations of Bena words and sentences during elicitation sessions on Bena L1. I have not taken into consideration written English produced using any text processing software as it is more likely to be distorted by the availability of a spell-checker. As I have not collected the written pieces produced by the consultants consistently, I can give only rough estimates for the written corpus. In total, the written data does not exceed a couple of thousand words. I would estimate that I encountered up to 10 occurrences of clause-final $t$ epenthesis and no examples of other types of epenthesis.

\section{BENA ENGLISH (L2) CONSONANTS}

This section provides an overview of the consonant systems of BE as L2. As expected for an L2 system, there is much variation in how well the reference native pronunciation of L2 forms is approximated, both between speakers with different levels of proficiency and within speakers depending on various sociolinguistic parameters involved in a given speech situation. Therefore, the system presented here necessarily represents an approximation of what I judge to be the typical speech patterns of a BE speaker with an average level of L2 proficiency, such as the Bena consultants I worked with on Bena L1. The description is based on my observations and recordings of spontaneous $\mathrm{BE}$ use.

The consonants found in word-initial position after a pause or the final vowel of a preceding word are summarized in table 1. 


\begin{tabular}{|c|c|c|c|c|c|c|c|c|c|c|c|c|c|}
\hline \multirow[b]{2}{*}{$\begin{array}{l}\text { stop \& } \\
\text { affricate }\end{array}$} & \multicolumn{2}{|c|}{ Bilabial } & \multicolumn{2}{|c|}{ Labiodental } & \multicolumn{2}{|c|}{ Alveolar } & \multicolumn{2}{|c|}{ Post-alveolar } & \multirow[t]{2}{*}{ Palatal } & \multicolumn{2}{|c|}{ Velar } & \multirow[t]{2}{*}{ Labial-velar } & \multirow{2}{*}{$\begin{array}{l}\text { Glottal } \\
\text { (P) }\end{array}$} \\
\hline & $\mathrm{p}^{\mathrm{h}}$ & b & & & $\mathrm{t}^{\mathrm{h}}$ & $\mathrm{d}$ & $\mathfrak{t} \int$ & क & & $\mathrm{k}^{\mathrm{h}}$ & g & & \\
\hline fricative & & & $\mathrm{f}$ & $\mathrm{V}$ & $\mathrm{S}$ & $\mathrm{Z}$ & $\int$ & (3) & & & & & $\mathrm{h}$ \\
\hline nasal & & $\mathrm{m}$ & & & & $\mathrm{n}$ & & & & & & & \\
\hline $\begin{array}{l}\text { trill / tap / } \\
\text { approximant }\end{array}$ & & & & & & $\mathrm{r}$ & & & & & & & \\
\hline $\begin{array}{l}\text { lateral } \\
\text { approximant }\end{array}$ & & & & & & 1 & & & & & & & \\
\hline $\begin{array}{l}\text { central } \\
\text { approximant }\end{array}$ & & & & & & & & & $\mathrm{j}$ & & & $(M) \mathrm{W}$ & \\
\hline
\end{tabular}

Table 1

Word-initial consonants in BE (before a vowel and after a pause or the final vowel of a preceding word)

In general, like in Bena L1, the aspiration of voiceless stops in BE is moderate, ${ }^{6}$ but more extreme realisations closer to the native English pattern are also possible. Utterance-initially, vowels are often pre-glottalised like in Bena L1. In careful speech, this prevocalic glottalisation may be preserved in phrase-internal position. It is possible that the sound classified as voiceless labialvelar approximant $[\mathrm{M}]$ in table 1 , as in what?, may be more accurately transcribed with an initial non-labialised phase as [hM] or [hw]. The phonological status of the glottal stop [?] is not clear. I do not know whether [3] occurs in this position.

Table 2 summarizes the word-final consonants as found before pause.

\begin{tabular}{|c|c|c|c|c|c|}
\hline $\begin{array}{l}\text { stop \& } \\
\text { affricate }\end{array}$ & $\begin{array}{l}\text { Bilabial } \\
\mathrm{p}^{(\mathrm{h})}\end{array}$ & Labiodental & $\begin{array}{l}\text { Alveolar } \\
\mathfrak{t}^{(\mathrm{h})}\end{array}$ & $\begin{array}{l}\text { Post-alveolar } \\
\mathfrak{t} \int\end{array}$ & $\begin{array}{l}\text { Velar } \\
\mathrm{k}^{(\mathrm{h})}\end{array}$ \\
\hline fricative & & $\mathrm{f}$ & S & $\int$ & \\
\hline nasal & $\mathrm{m}$ & & $\mathrm{n}$ & & (y) \\
\hline $\begin{array}{l}\text { lateral } \\
\text { approximant }\end{array}$ & & & 1 & & \\
\hline
\end{tabular}

Table 2

Word-final consonants in BE before pause

\footnotetext{
${ }^{6}$ The aspiration may be lacking in word-initial clusters with [r] as the second element, as in three [ $\mathrm{t}^{\mathrm{a}} \mathrm{r}$ ] in figure 15 below.
} 
As other varieties of NE, BE is generally non-rhotic. ${ }^{7}$ Even though Bena L1 does have a velar nasal, in BE the etymological velar nasal tends to be replaced by the alveolar nasal stop [n], as is typical for NE in general (cf. Gut 2008:45). However, in BE the preservation of [y] seems to be largely dependent on stress. Thus, [n] is consistently replaced by [n] in BE in words such as evening, morning, nothing, looking, where the relevant syllable is not stressed (similarly to general English "g-dropping" in unstressed syllables), while [ $\mathrm{y}]$ is often preserved in words such as in king, young, thing or belong, where the relevant syllable is stressed. BE is characterised by pre-pausal devoicing, since only voiceless stops, fricatives and affricates occur word-finally before pause, resembling the Bena L1 pattern. Unlike in Bena but like in more standard varieties of NE, as well as British RP English (Buizza \& Plug 2012), pre-pausal stops normally have audible release which may be strong enough to qualify as aspiration (figure 1a), and pre-pausally, occasionally even as a slight affrication (figure 1b). At times, pre-pausal oral stops are glottalised

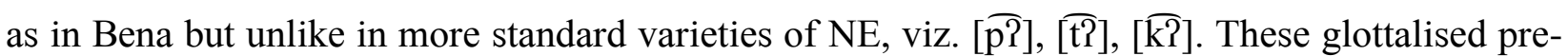
pausal stops may have an audible release, as illustrated in figure 2, and sometimes this release is nasal. As becomes apparent from the comparison of figures $(1 \mathrm{a}, \mathrm{b})$ and figure 2 , the aspirated and affricated pronunciations are characterised by a much shorter closure duration, similar to what

\footnotetext{
${ }^{7}$ However, I did encounter occasional examples of a word-final [r], such as [keər] 'care'.
} 
one finds in more standard varieties of NE, whereas the closure duration of the glottalised variant
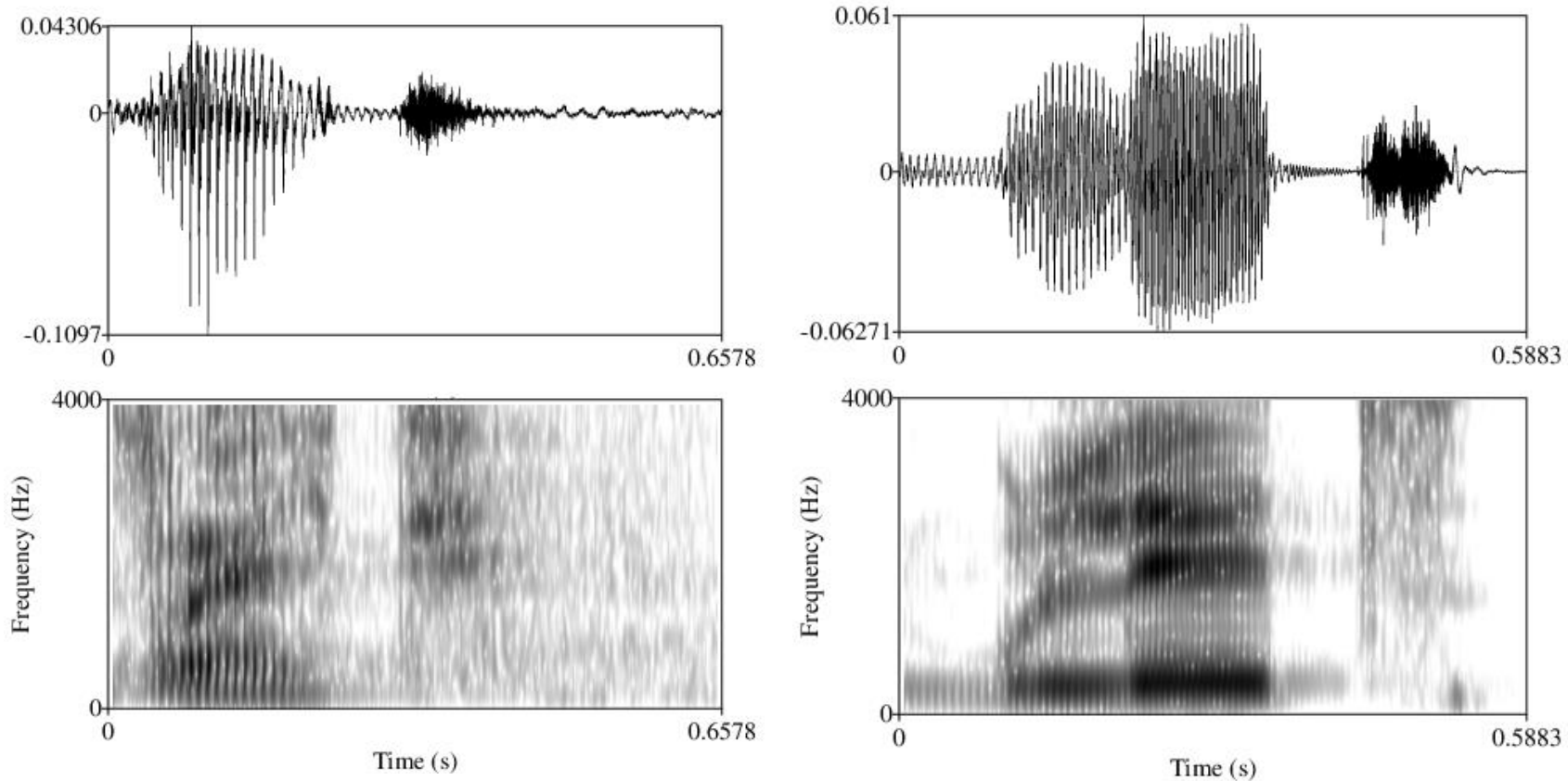

Figure 1a

right with aspirated $\left[t^{h}\right]$

Figure 1b

(re)gulate with affricated $\left[t^{s}\right]$
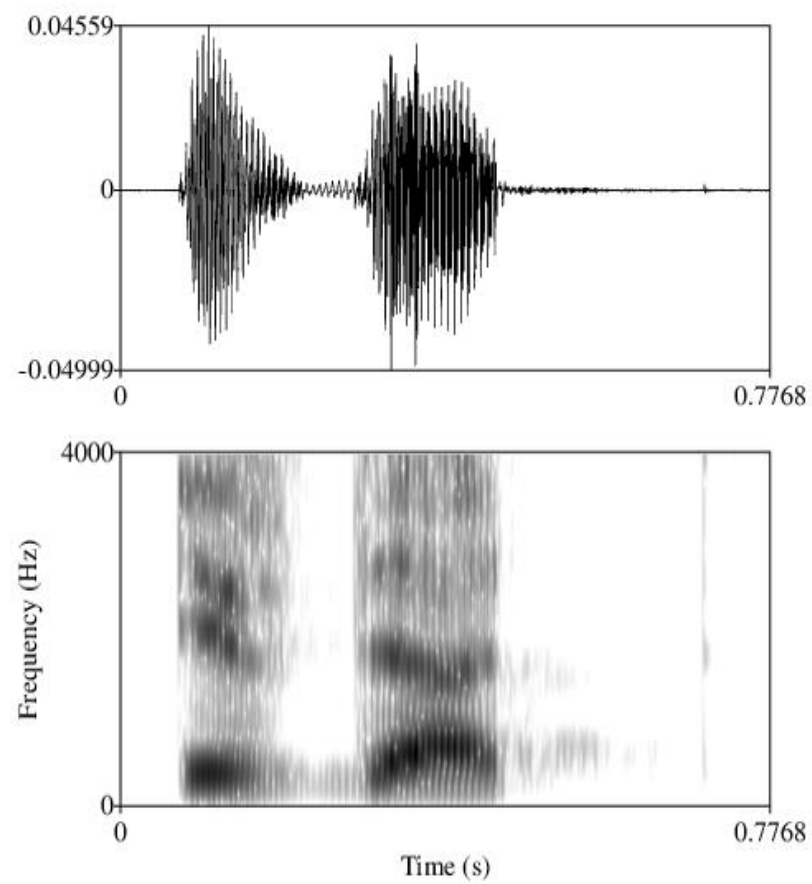

Figure 2

is that with an audible release of $\overleftarrow{t ? 7}$ 
is comparable to what one finds for pre-pausal glottalised stops in Bena.

Pre-pausal continuants, nasals and the lateral in BE appear to be realised largely similarly to Bena. Thus, like in Bena, they may be considerably lengthend, as [f] of have in figure 3.

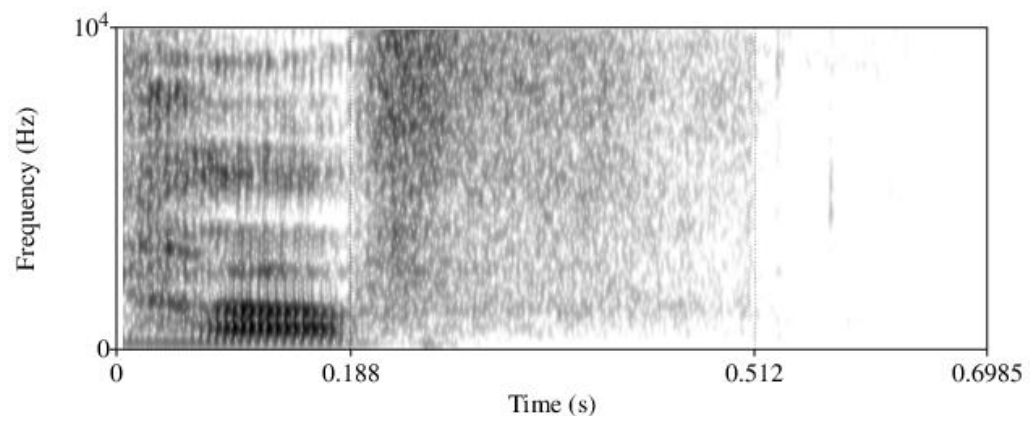

Figure 3

[f] of have

With nasals and [1] the fall in intensity is not continuous from the vowel into the consonant but tends to occur in one or two steps composed of a brief period of slightly rising or flat intensity curve and a subsequent significant downtrend, as illustrated in figures 4 and 5 . In other words, although strictly speaking nasals and [1] are not devoiced, the overall decreasing trend in their acoustic energy that sets in very early may, from the acoustic point of view, be considered analogous to the full lack of voicing observed with the stops and fricatives.

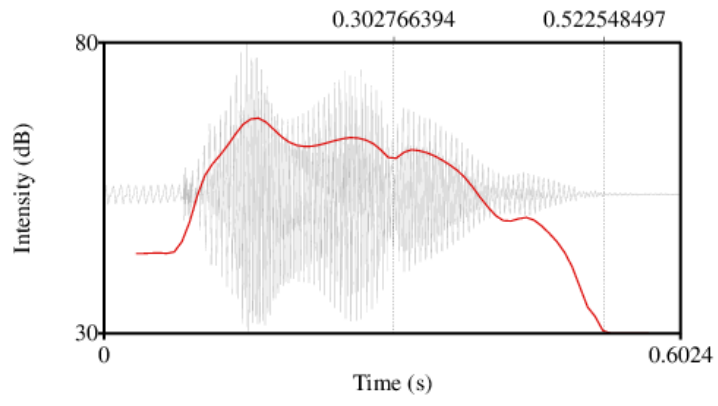

Figure 4

girl [geal]

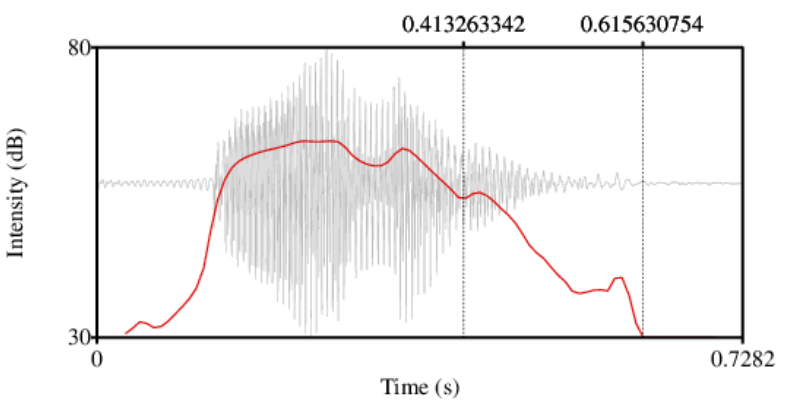

Figure 5

demon [demon]

Furthermore, similarly to other consonants, pre-pausal continuants, nasals and the lateral are occasionally followed by a glottal closure and an audible release, as illustrated in figures 6 and 7, where the presence of glottalisation is also supported in the acoustic record by a more abrupt final fall in the intensity curve without the second step observed in figures 4 and 5. Such glottalisation of pre-pausal continuants, nasals and the lateral is also found in Bena, where it 
seems to be more common.

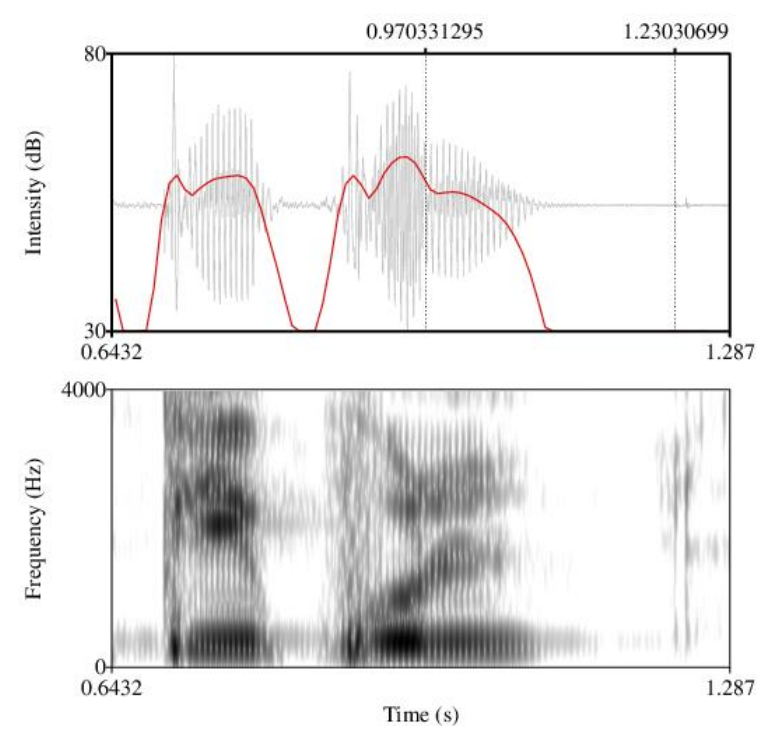

Figure 6.

people $\left[p^{h} i p^{h} U 1 P\right]$

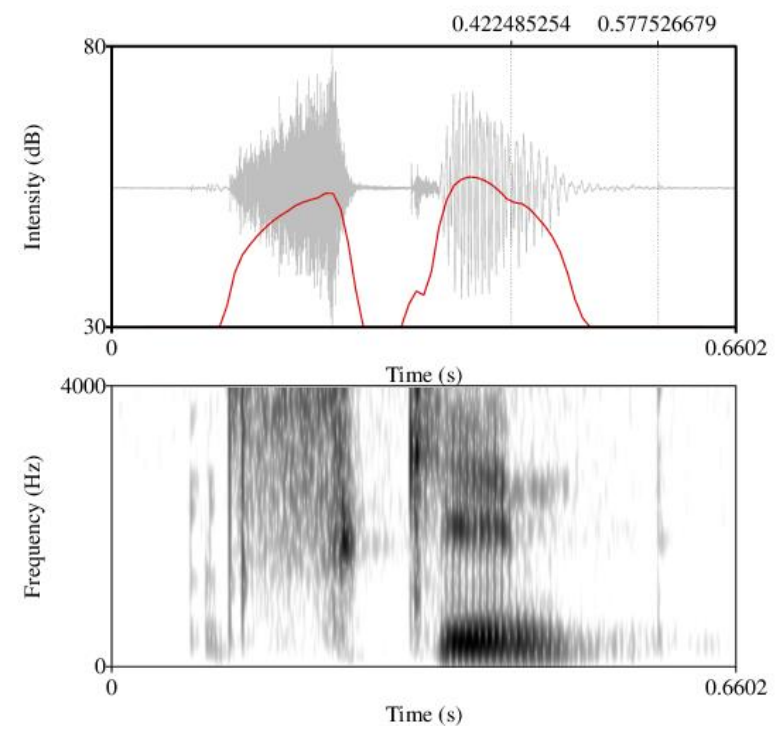

Figure 7

skin [Sk ${ }^{h}$ in?]

Many types of word-final consonant clusters, but not word-initial or word-internal ones, are regularly simplified in BE irrespective of the phonological context to the right of the word in question, largely in the same way as in more standard varieties of NE (cf. Simo Bobda 2007, Gut 2009a, 2009b, Ugorji 2010) and Nigerian Pidgin English (cf. Faraclas 1996). One strategy involves insertion of a non-etymological vowel, mostly for clusters involving a lateral approximant and a non-coronal consonant, as in [ $\mathrm{p}^{\mathrm{h}} \mathrm{ip} \mathrm{p}^{\mathrm{h}} \mathrm{ul}$ ] 'people' in figure 6 (assuming that 'people' has the structure /pipl/). In clusters with a final stop homorganic to the first consonant or with more than two consonants involved, consonant deletion is the regular strategy. It is normally the final consonant that drops out, as in spen(t) in $(1 \mathrm{~g})$ and husban(d) in (1h). Other types of clusters normally remain intact, e.g. clusters involving non-homorganic fricatives and stops, as in [aks] 'ask', [riks] 'risk(s)' (also showing a metathesis of the etymological sk sequence), [waps] 'wasp' (also showing a metathesis of the etymological $s p$ sequence), [teks] 'text(s)', left, and clusters with a nasal, lateral or stop followed by a homorganic fricative (viz. [s] or [S]) or affricate (viz. [t]]), as in else, prince ${ }^{8}$ or $A I D S$.

Table 3 summarizes the word-final consonants in contexts other than before pause.

\footnotetext{
${ }^{8}$ Admittedly, the nasal in a cluster such as [ns] of prince is often completely replaced by the nasalisation of the preceding vowel, resulting in [ $\mathrm{p}^{2} \mathrm{r}$ s $]$, in which case of course one cannot speak about a cluster.
} 


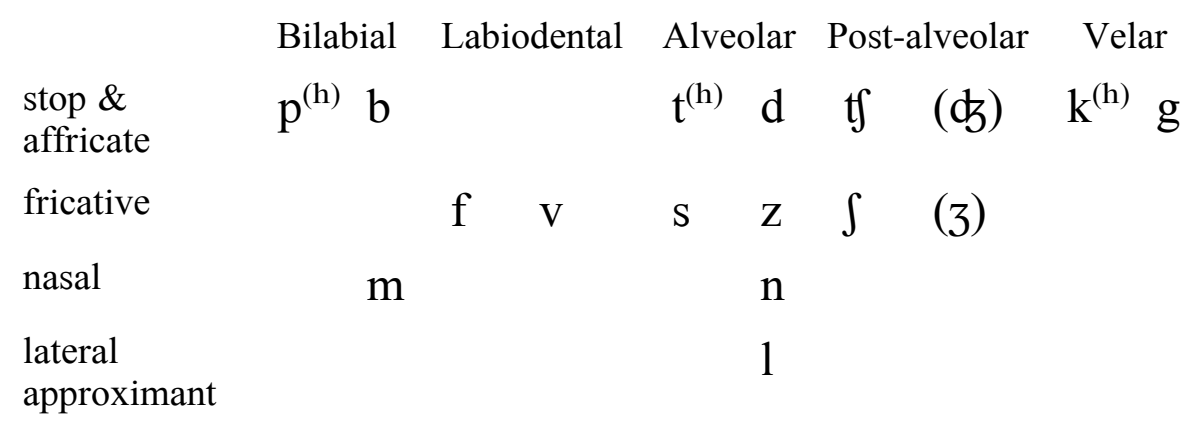

Table 3

Word-final consonants in BE not before pause

We find in table 3 the same consonants as in the pre-pausal context in table 2 with the additional possibility of voicing for the stops and fricatives (I do not know whether the voiced affricate [b] and the voiced fricative [3] are possible in this position).

\section{BENA (L1) CONSONANTS}

This section provides an overview of the consonant systems of Bena as L1 (cf. also Van de Velde \& Idiatov 2017). One consonant, the labiodental flap [ $\mathrm{V}$ ], occurs only word-internally and therefore does not show up in the tables below.

The consonants found in word-initial position after a pause or the final vowel of a preceding word are summarized in table 4.

\begin{tabular}{|c|c|c|c|c|c|c|c|c|c|c|c|c|c|}
\hline & Bilab & & Labic & dental & Alve & olar & Postalveolar & Palatal & Velc & & Labial & velar & Glottal \\
\hline $\begin{array}{l}\text { plain stop \& } \\
\text { affricate }\end{array}$ & $\mathrm{p}^{\mathrm{h}}$ & b & & & $\mathrm{t}^{\mathrm{h}}$ & d & $\mathfrak{t}$ & & $\mathrm{k}^{\mathrm{h}}$ & $\mathrm{g}$ & $\widehat{\mathrm{kp}}$ & $\mathrm{gb}$ & (?) \\
\hline implosive & & 6 & & & & d & & & & & & & \\
\hline fricative & & & f & $\mathrm{V}$ & $\mathrm{S}$ & z & $\int$ & & & & & & $\mathrm{h}$ \\
\hline nasal & & $\mathrm{m}$ & & & & $\mathrm{n}$ & & & & y & & $\overline{\mathrm{ym}}$ & \\
\hline $\begin{array}{l}\text { trill / tap / } \\
\text { approximant }\end{array}$ & & & & & & $\mathrm{r}$ & & & & & & & \\
\hline $\begin{array}{l}\text { lateral } \\
\text { approximant }\end{array}$ & & & & & & 1 & & & & & & & \\
\hline central & & & & & & & & $\mathrm{j}$ & & & & $\mathrm{W}$ & \\
\hline approximant & & & & & & & & $\tilde{\jmath}$ & & & & $\tilde{\mathrm{W}}$ & \\
\hline
\end{tabular}

Table 4

Word-initial consonants in Bena (before a vowel and after a pause or the final vowel of a preceding word) 
The aspiration of voiceless stops is moderate. Utterance-initially, vowels are often pre-glottalised. In careful speech, this prevocalic glottalisation may be preserved in phrase-internal position. Utterance-initially, all voiced stops, with the exception of the labial-velar stop but including implosives, and especially voiced fricatives may be partially or fully devoiced. The approximants and nasals are not strictly speaking devoiced but can start with a period of a significantly reduced acoustic energy, which in the acoustic record looks largely like the mirror image of what happens word-finally before pause and has been described in section 3 for BE. As a result, the nasal central

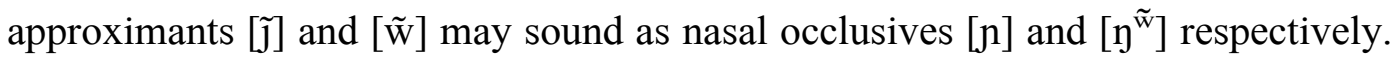

Table 5 summarizes the word-final consonants as found before pause.

\begin{tabular}{|c|c|c|c|c|c|c|c|}
\hline stop & $\begin{array}{l}\text { Bilabial } \\
\overparen{\text { p? }}\end{array}$ & Labiodental & $\begin{array}{l}\text { Alveolar } \\
\overparen{\mathrm{t} ?} \\
\left(\mathrm{t}^{(\mathrm{h})}\right)\end{array}$ & Palatal & $\begin{array}{l}\quad \text { Velar } \\
\widehat{\mathrm{k} ?} \\
\left(\mathrm{k}^{(\mathrm{h})}\right)\end{array}$ & Labial-velar & $\begin{array}{c}\text { Glottal } \\
\text { (?) }\end{array}$ \\
\hline fricative & & $\mathrm{f}(\mathrm{P})$ & $\mathrm{s}(\mathrm{P})$ & & & & \\
\hline nasal & $\mathrm{m}(\mathrm{P})$ & & $\mathrm{n}(\mathrm{P})$ & & $\eta(?)$ & & \\
\hline trill & & & $\mathrm{r}(\mathrm{P})$ & & & & \\
\hline $\begin{array}{l}\text { lateral } \\
\text { approximant }\end{array}$ & & & $1(?)$ & & & & \\
\hline central & & & & $\mathrm{j}(\mathrm{P})$ & & $\mathrm{w}(\mathrm{P})$ & \\
\hline approximant & & & & $\tilde{\mathrm{j}}(\mathrm{P})$ & & $\tilde{\mathrm{W}}(\mathrm{P})$ & \\
\hline
\end{tabular}

Table 5

Word-final consonants in Bena before pause

Bena is characterised by pre-pausal devoicing. Furthermore, pre-pausal glottalisation is regular with stops. The glottal closure may have a weak audible release. If the oral closure is bilabial, the audible release is nasal. After oral stops and nasals with alveolar or velar closure, it can be nasal or non-nasal. In some words ending with an alveolar or velar oral stop that typically occur clausefinally and therefore also utterance-finally, such as ideophones and adverbs, the oral closure, especially the velar one, may be audibly released just before the glottal closure resulting in a weakly ejective sound, as in [ kpát ák̂́k át ák'] 'bitter' in figure 8 . 

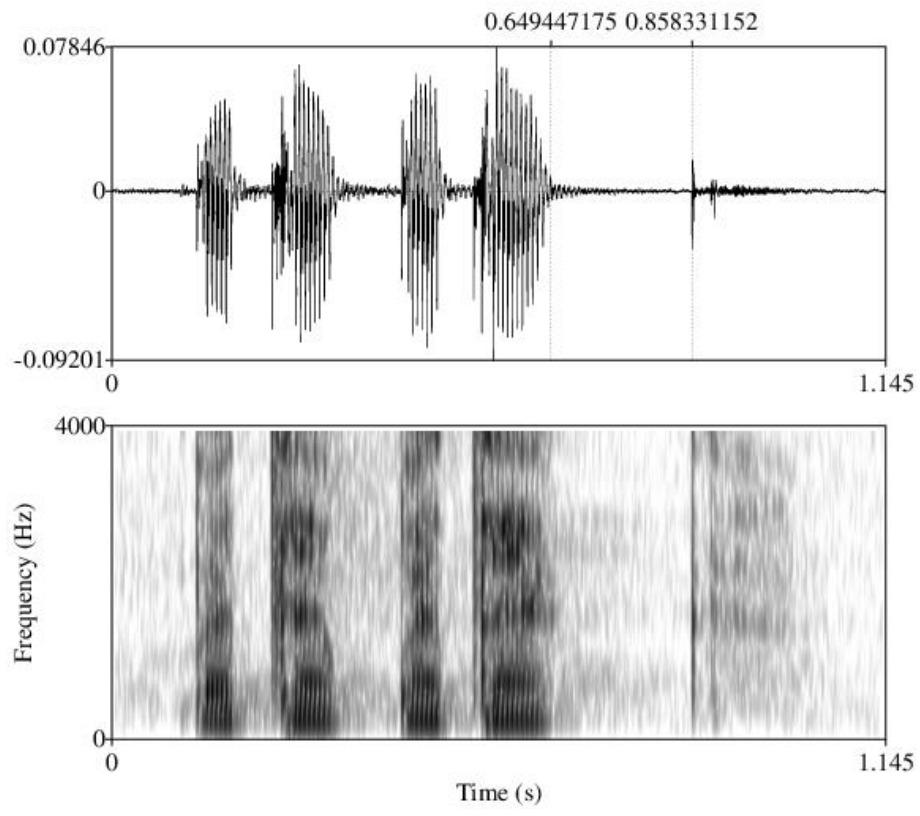

Figure 8

[kpát ákpáthák'] 'bitter' with a weakly ejective release

of a pre-pausal glottalised velar stop

Furthermore, occasionally, pre-pausal glottalisation is lacking with these words, as in [sāk ${ }^{\mathrm{h}} \overline{\mathrm{a}} \mathrm{t}^{\mathrm{(h})}$ ] 'quickly' figure 9, or at least reduced in duration, as in [sāk $\overline{\mathrm{a}} \overline{\mathrm{t}}$ ] 'quickly' figure 10. The burst of the audible release of the oral closure is then usually weak but may be followed by noisy airflow that sometimes sounds as slight aspiration.

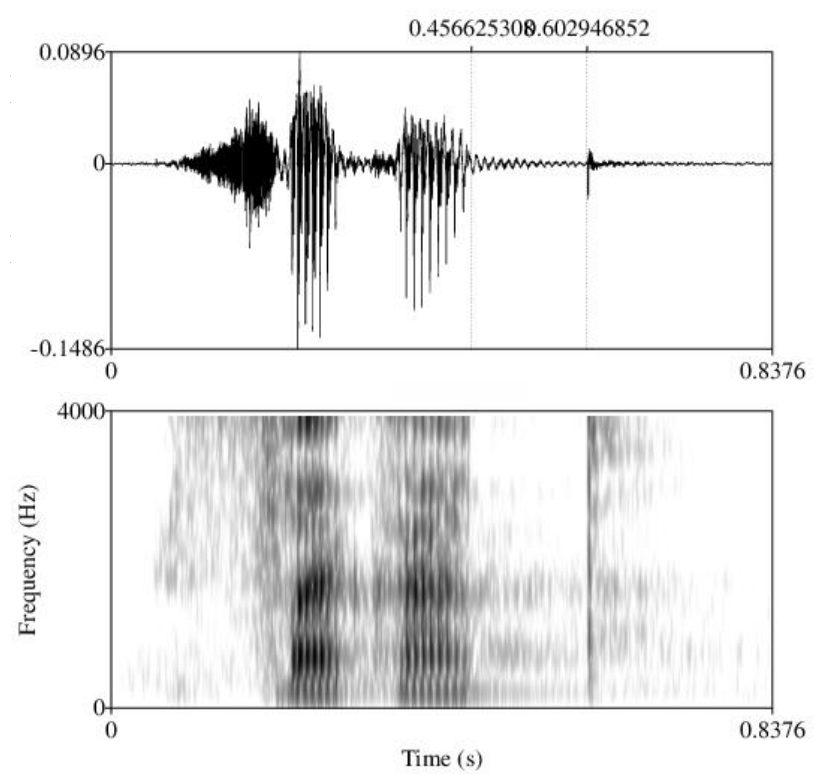

Figure 9

[sāk $\left.{ }^{h} \bar{t}^{(\boldsymbol{h})}\right]$ 'quickly'
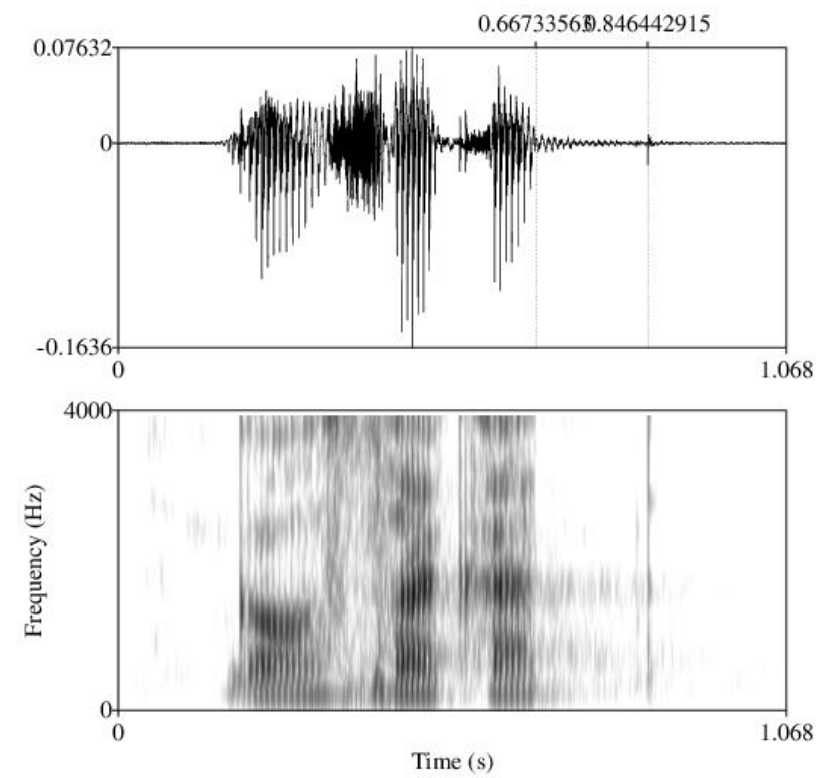

Figure 10

[gàw sāk $\left.{ }^{h} \bar{a} \hat{t}\right]$ 'come quickly!' 
Pre-pausal glottalisation also occurs with continuants, nasals, [1] and vowels, as illustrated in figures 11 and 12 for [s?] and [n?] respectively. However, given that an audible release may be lacking, it is difficult to judge how common it is without articulatory data.
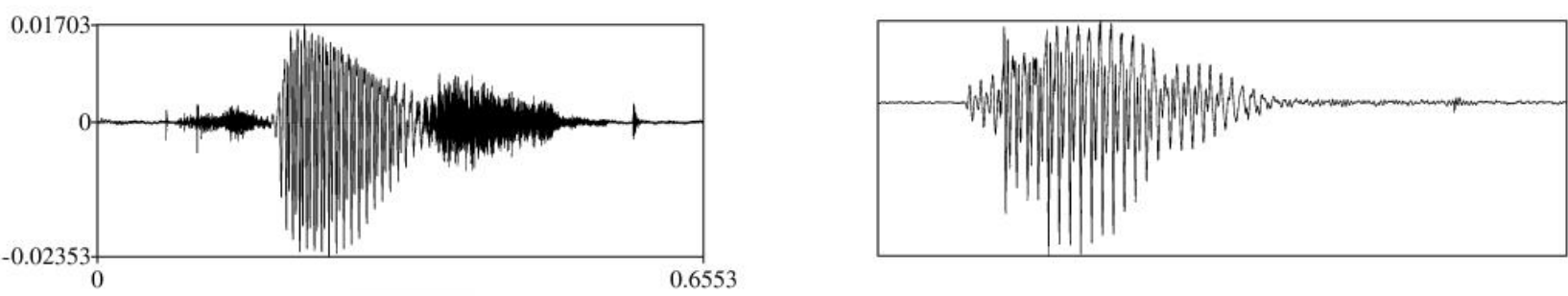

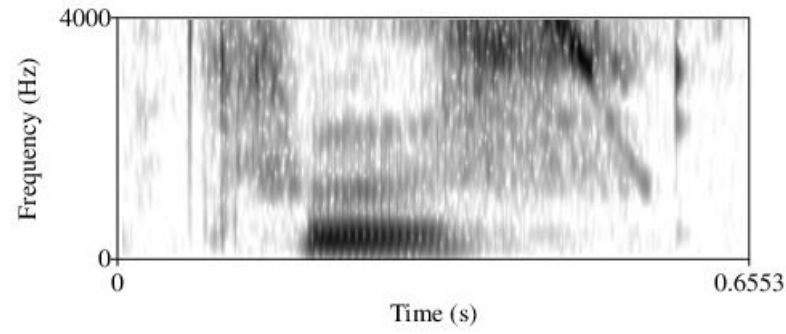

Figure 11

[(bî) $t_{0}^{h}$ rùs?] (a proper name) with an audible release of [S?]

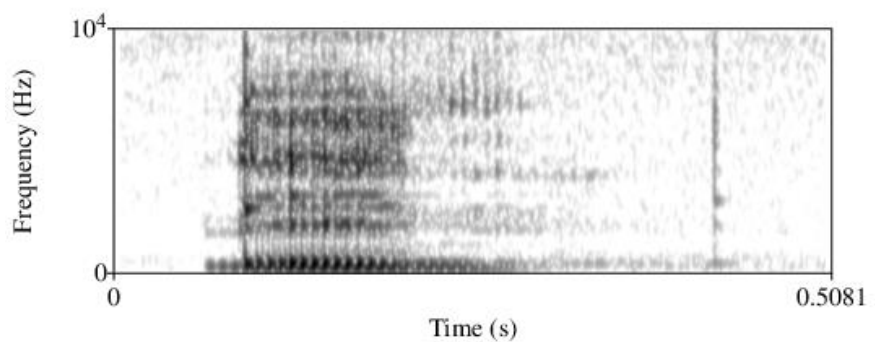

Figure 12

[dèn?] 'tomorrow' with an audible release of [n?]

Similarly to what was described in section 2 for BE pre-pausal sonorants [m], [n] and [1], in Bena even in the absence of an audibly released glottal closure, before pause these sonorants tend to show the same early decreasing trend in their intensity that from the acoustic point of view may be considered analogous to the full lack of voicing observed with other consonants.

Consonant lengthening is another important phonetic property associated with the prepausal position. ${ }^{9}$ With continuants, nasals and the lateral such a lengthening is apparent in figures 11 and 12 above and is also illustrated in table 6 by comparing two instances of [nōn] '1SG.IPFV', one phrase-internal, before a following [s] and one before pause in a word-by-word repetition of the same utterance. A continuant, nasal and the lateral before pause can be almost twice as long

\footnotetext{
${ }^{9}$ Although reminiscent of utterance-final lengthening, pre-pausal consonant lengthening in Bena must be a different kind of phenomenon, at least if utterance-final lengthening is conceived as a reflection of a general tendency to decelerate towards the end of an utterance. The degree of lengthening of pre-pausal consonants in Bena is too strong to be attributed to a mechanic synchronic effect of deceleration. In my view, the explanation in Bena (and probably similar cases cross-linguistically) is historical rather than synchronic. Pre-pausal consonant lengthening in Bena is primarily of compensatory origin and related to the loss of final vowels in this position. While final vowel loss has been generalized in the relevant words, consonant lengthening has been generalized to all consonants before a pause.
} 
as the same consonant elsewhere. Thus, in table 6 the pre-pausal [n] has the duration of $190 \mathrm{~ms}$, as opposed to the duration of [n] of $105 \mathrm{~ms}, 115 \mathrm{~ms}$ and $123 \mathrm{~ms}$ in the other positions.

$\begin{array}{llll} & {[\mathrm{n}} & \bar{\partial} & \mathrm{n}] \\ \text { pause _ }[\mathrm{s} . . .] & 115 \mathrm{~ms} & 80 \mathrm{~ms} & 123 \mathrm{~ms} \\ \text { pause _ pause } & 105 \mathrm{~ms} & 103 \mathrm{~ms} & 190 \mathrm{~ms}\end{array}$

Table 6

Phrase-internal vS. pre-pausal instance of [n̄̄n] '1SG.IPFV'

Similarly, (audibly released) pre-pausal glottalised stops have a considerably longer closure than their non-glottalised counterparts and the stops of the same place of articulation elsewhere. Thus, the closure duration of a non-glottalised [ $\left.\mathrm{t}^{(\mathrm{h})}\right]$ in figure 9 is $146 \mathrm{~ms}$ as opposed to $179 \mathrm{~ms}$ of a (partially) glottalised [t?] in figure 10 and $234 \mathrm{~ms}$ of a more clearly glottalised (and probably weakly ejective) [t?] in figure 13 .

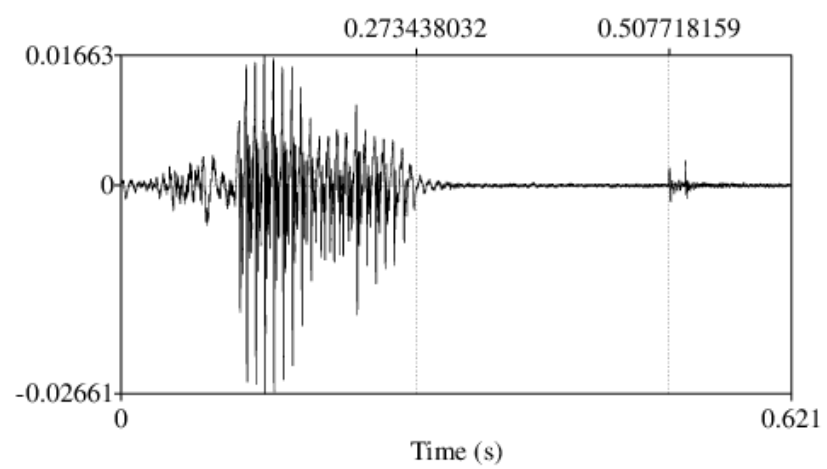

Figure 13

[pwàrăt?] 'already'

As I argue in section 6, the phonetic properties of Bena L1 described above, such as pre-pausal glottalisation and lengthening of consonants, allow us to better understand the details of the hypercorrection scenario for the emergence of the BE pattern.

Table 7 summarizes the word-final consonants in contexts other than before pause. 


\begin{tabular}{|c|c|c|c|c|c|c|c|c|c|c|c|}
\hline & Bila & & & dental & & eolar & Palatal & $\mathrm{Ve}$ & & Labial-velar & Glottal \\
\hline plain stop & $\mathrm{p}$ & b & & & $\mathrm{t}$ & d & & $\mathrm{k}$ & $\mathrm{g}$ & & (?) \\
\hline implosive & & 6 & & & & d & & & & & \\
\hline fricative & & & $\mathrm{f}$ & $\mathrm{V}$ & $\mathrm{s}$ & $\mathrm{Z}$ & & & & & \\
\hline nasal & & $\mathrm{m}$ & & & & $\mathrm{n}$ & & & $y$ & & \\
\hline trill & & & & & & $r$ & & & & & \\
\hline $\begin{array}{l}\text { lateral } \\
\text { approximant }\end{array}$ & & & & & & 1 & & & & & \\
\hline central & & & & & & & $\mathrm{j}$ & & & $\mathrm{W}$ & \\
\hline approximant & & & & & & & $\tilde{\jmath}$ & & & $\tilde{\mathrm{W}}$ & \\
\hline
\end{tabular}

Table 7

Word-final consonants in Bena not before pause

There are no (pre-pausal or phrase-internal) word-final consonant clusters in Bena, although consonant clusters are possible across word boundaries and within words, both across syllable boundaries and in syllable onsets. In their citation form, most words end in an open syllable. Final closed syllables are more common in minor part of speech classes, such as adverbs. Utteranceinternally, the final vowels are often reduced and in some constructions deleted. For instance, this is what happens with the final vowel of the head N1 in a genitive construction N1 N2. When the final vowel is deleted, the result is a word-final closed syllable. At least in the case of the genitive construction, the resulting final consonant is optionally glottalised comparably to the pre-pausal context.

\section{THE PHONETICS AND PHONOLOGY OF WORD-FINAL POST-CORONAL $t$ AND $s$ EPENTHESIS IN BE}

\section{1. $\mathrm{t}$ and $\mathrm{s}$ epenthesis: contexts}

Most examples of word-final post-coronal $t$ and $s$ epenthesis in BE are found before utterancefinal pause. Thus, before a pause, [t] was only found inserted after the word-final alveolar coronals [n], [1] and [s], whereas [s] was only found inserted after a word-final alveolar coronal stop [t] and an alveolar coronal [1]. The few examples of phrase-internal word-final post-coronal $t$ and $s$ epenthesis I recorded, occur before a vowel, also an epenthetic one, as in the case of a wordinitial [r] in example (2d) above, or an approximant, as in (2a). This means that, phrase-internally, $t$ insertion has been found after [n] and $s$ insertion has been found after [n] and [1]. Examples of

$t$ and $s$ epenthesis are found with words of basically any part of speech and in both stressed and 
unstressed syllables, as illustrated in examples (1) and (2) with nouns, verbs, an adjective, a demonstrative, a conjunction and an adverb with both stressed and unstressed final syllables.

Some cases of non-etymological word-final $t$ and $s$ can be argued to be examples of the spurious -ed and $-s$ suffixes. Thus, in (3a) the non-etymological $t$ can be said to be the past tense marker -ed wrongly applied to the verb run. Similarly, in (3b) the non-etymological $s$ can be said to be the nominal plural marker $-S$ wrongly applied to the plural form children. In $(3 \mathrm{c})$, the nonetymological $s$ can be argued to be the nominal plural $-s$ suffix with a mass nominal expression wrongly construed as count. In (3d) and (3e), the non-etymological $s$ appears to be the verbal third person singular $-s$ suffix wrongly used with the plural subject that refers to a group. In (3f), the non-etymological $s$ can be argued to be the nominal plural $-s$ suffix whose use here may reflect a confusion between some certain kind of sticks and some certain stick.
(3) (a) He run[t]
(b) They eat children[s]
(c) The private sector[s]
(d) The church elders say[z] it
(e) Some people feel[s] like...
(f) And there is some certain stick[s] that we have. We call it kārēe.

If we disregard such examples of the spurious -ed and $-s$ suffixes, the possibility of $t$ and $s$ epenthesis, both before pause and phrase-internally, depends solely on whether the word-final consonant is alveolar coronal or not. The only potential exception to this generalisation is prepausal labio-dental fricative [f]. Thus, Mark Van de Velde has reported (p.c.) that he observed one case of pre-pausal $t$ epenthesis after [f] in the phrase I do not drink cold water because of $\operatorname{cough}[\mathrm{t}]$. I do not have such examples in my data.

\section{2. $\mathrm{t}$ and $\mathrm{s}$ epenthesis: phonetics}

The audible release of a pre-pausal epenthetic [t] is generally weak without any accompanying noisy airflow, as illustrated in figure 14. In this respect, it is comparable to Bena pre-pausal [t?] rather than $\left[\mathrm{t}^{(\mathrm{h})}\right]$. The audible release can also be nasal, as in three days $\left[\mathrm{t}^{\mathrm{n}}\right]$ in figure 15 , comparably to Bena pre-pausal $\left[\right.$ t? $\left.^{\mathrm{n}}\right]$. 

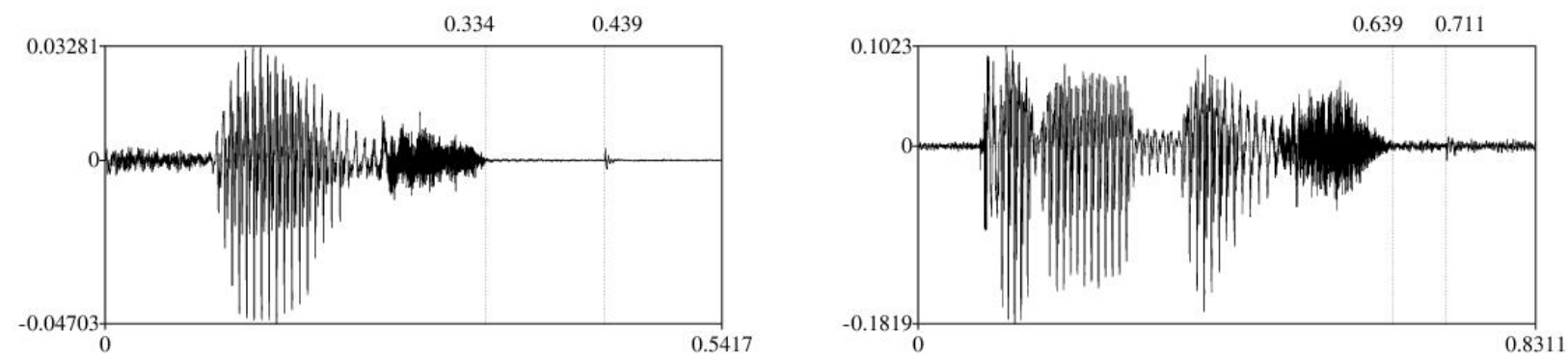

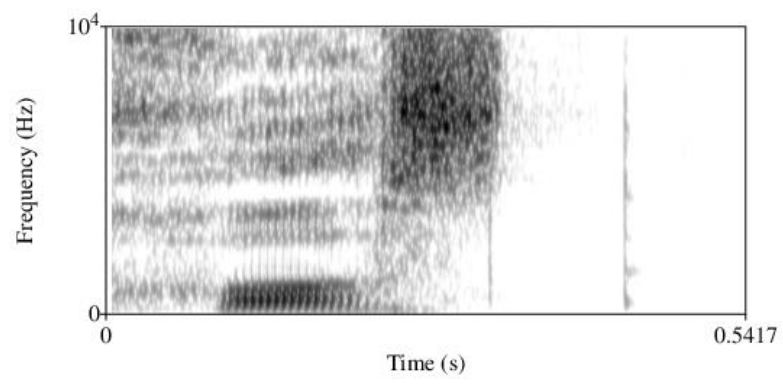

Figure 14

horse [host]

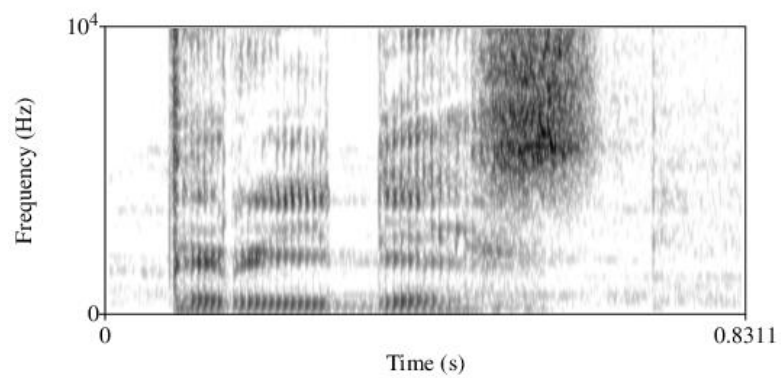

Figure 15 three days [ $\left.t \boldsymbol{t} r i \operatorname{des} t^{p}\right]$

Acoustically, the difference between the audibly released pre-pausal epenthetic [t] in BE and the audibly released pre-pausal glottalised [t?] in Bena appears to be primarily that of closure duration. Thus, the closure duration of BE epenthetic $[\mathrm{t}]$ is much shorter (e.g., $105 \mathrm{~ms}$ in figure 14 and $72 \mathrm{~ms}$ in figure 15) and comparable to that of a non-glottalised [ $\left.\mathrm{t}^{(\mathrm{h})}\right]$ in Bena or BE, suggesting that it is equally not accompanied by a glottal closure or only marginally so.

Within a word-final consonant cluster, the audible release of the word-final $-t$ that has not been deleted before a pause ranges from a relatively strong one, $\left[\mathrm{t}^{(\mathrm{h})}\right]$, similar to a word-final postvocalic $-t$ (cf. section 3 ), to a very weak one, without any accompanying noisy airflow, similar to a pre-pausal epenthetic [t], as illustrated in figure 16 with a pre-pausal instance of the word husband where the release burst in the lexical cluster [nt] is very weak. 

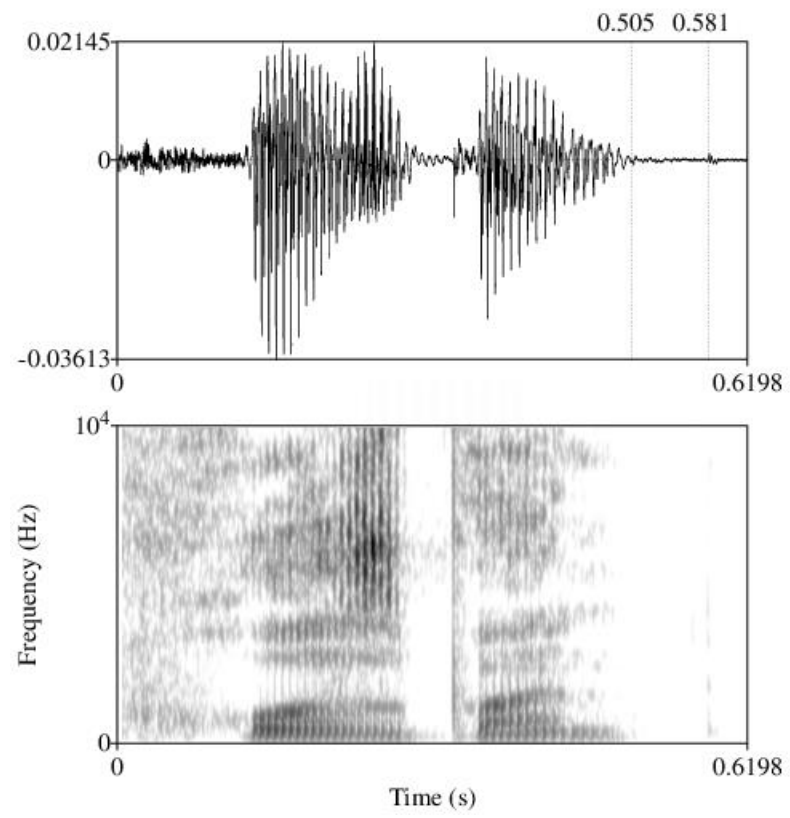

Figure 16.

husband [hozbant]

I observed no obvious acoustic differences between pre-pausal epenthetic [s], phraseinternal word-final epenthetic $[\mathrm{t}]$ and $[\mathrm{s}]$ and their non-epenthetic counterparts in these contexts in terms of duration, intensity, burst quality and VOT.

Several studies dealing with the phonetic implementation of epenthetic stops as compared to that of their non-epenthetic counterparts in consonant clusters, such as Fourakis \& Port (1986) for American English, Warner \& Weber (2001) for Dutch and Recasens (2012) for Valencian Catalan, have argued that the two kinds of stops are produced differently. Such studies also argued that differences in production go along with differences in perception. When no differences in production were observed, no differences in perception were found either, as in Lee (1991) and Yoo \& Blankenship (2003) for American English. At the same time, differences in perception may not translate straightforwardly into differences in categorization. Thus, in Warner \& Weber's (2001) study epenthetic stops were perceptible to the speakers "as tokens of the stop phoneme, a great deal of time", even though they were still perceived "far less often" and "perceived far more slowly" than their non-epenthetic counterparts. The lack of obvious acoustic differences between epenthetic and non-epenthetic $[\mathrm{t}]$ and $[\mathrm{s}]$ in BE makes it unlikely that $[\mathrm{t}]$ and $[\mathrm{s}]$ from the two sources are discriminable in perception. Consequently, it is also unlikely that they differ in their categorization, especially given that the non-epenthetic counterparts of the epenthetic [t] 
and $[\mathrm{s}]$ in BE optionally undergo deletion themselves. In other words, from a BE learner's perspective the epenthetic consonants are likely to be categorized as an optional part of the phonological representation similarly to their non-epenthetic counterparts that optionally undergo deletion. The main difference is then probably in the lower probability of realization associated with the epenthetic consonants.

\section{3. $\mathrm{t}$ and $\mathrm{s}$ epenthesis: phonological status}

Two questions arise with respect to the phonological status of the word-final post-coronal $t$ and $s$ epenthesis in BE. Given that the epenthesis is optional and the context of its application can be described in strictly phonological terms, the first question is whether the speakers have phonological awareness of the epenthetic consonants, that is whether the epenthetic consonants make (optional) part of the phonological representation. ${ }^{10}$ I believe they do. The following evidence can be adduced to support this conclusion.

As discussed in section 5.2, the lack of obvious acoustic differences between epenthetic and non-epenthetic $[\mathrm{t}]$ and $[\mathrm{s}]$ suggests that the epenthetic consonants are likely to be categorized similarly to those of their non-epenthetic counterparts that optionally undergo deletion as optional part of the phonological representation. While the insertion is optional and some speakers are more prolific than others (as was one of my three primary consultants), both better overall English proficiency and more formal situations of English use appear to reduce the amount of epenthesis. At the same time, my impression is that the decrease in the amount of the epenthesis for a given speaker in such situations is not accompanied by a noticeable increase in production of etymological word-final clusters with $t$ and $s$. That is, in such situations speakers appear to approximate the pronunciation of more standard varieties of NE in terms of cluster simplification tendencies. This decrease in the amount of the epenthesis in a particular type of situations of language use, viz. more formal situations, may be interpreted in favour of the speakers' phonological awareness of the epenthesis. More direct evidence in favour of the phonological awareness interpretation is provided by the fact that at least the utterance-final epenthetic $[\mathrm{t}]$ has

\footnotetext{
${ }^{10}$ The answer to this question is not as obvious as it may seem at first sight. In this respect, compare a similar question on the phonological status of the epenthetic stops that are occasionally heard in (American) English between homorganic nasal or lateral and fricative in words such as teamster ['thimpstə]'. Ohala (1986: 16-8) argues that in most cases these epenthetic stops are surface phonetic phenomena, even though occasionally they may become phonologised and "through sound change" enter "the speaker's mental lexicon", as in dempster vs. deemster or as reflected in the alternative spellings (and pronunciations) of the name Thompson vs. Thomson.
} 
been found reflected in written BE, as in (4), where the spelling find has been used in an email exchange by the speaker on three occasions clause-finally instead of fine.

\section{(4) I hope you are all find.}

As a possible argument against the phonological status of the epenthesis I must mention the fact that I was unable to directly confirm through elicitation with my consultants that for a given word both the form without epenthesis and the form with epenthesis co-exist as options, or that only the form with epenthesis is acceptable. ${ }^{11}$ However, I believe that the primary reason for this is not that the epenthetic $t$ and $s$ do not make part of the BE phonology but that a post-consonantal word-final $t$ or $s$ is not normally used to differentiate lexical meanings in spontaneous BE. In this respect, it is instructive that I often had similar difficulties eliciting certain types of word-internal nasal-voiced stop clusters in Bena even from the speakers whom I recorded using them spontaneously. The nasal in such a cluster is not distinctive and is often dropped.

Given the positive answer to the question of whether the epenthetic consonants make (optional) part of the phonological representation and the tendency for word-final cluster simplification in BE (cf. section 3), the second question that may be asked with respect to the phonological status of the word-final post-coronal $t$ and $s$ epenthesis in BE is whether it is a case of hypercorrection, that is basically a mistake in an attempt to approximate the pronunciation of more standard varieties of $\mathrm{NE}$, and in this sense, a pattern that is alien to the system of BE. I argue that from the synchronic perspective, the hypercorrection analysis is inadequate and that we are rather dealing here with optional phonological rules within the system of BE, as formulated in (5-8) in terms of segments (a) or features (b). In other words, even though BE speakers are L2 speakers, it is a speech-community level phenomenon, and not (anymore) just a language-learning issue.

\footnotetext{
${ }^{11} \mathrm{BE}$ is an L2 and my consultants explicitly judged my L2 English as necessarily more correct than theirs. In a situation like this, a direct question from me of the kind Do you say $W$ or $W[\mathrm{t}]$ ? Or maybe both are $o k$ ? for a given word $\mathrm{W}$ is likely to make sense only for words about which the consultants may be expected to consider themselves more knowledgeable than me, such as the names of Nigerian cities, for instance Jos, the capital of the Plateau state. In such cases, the consultants confirmed the form without epenthesis, even though outside of elicitation situations the same speakers did occasionally produce the form with epenthesis.
} 
(5) pre-pausal $t$ epenthesis

(a) $\varnothing \rightarrow \mathrm{t} /\{\mathrm{n} 1 \mathrm{~s}\}_{\text {_ }} \#_{\text {pause }}$

(b) $\varnothing \rightarrow\left[\begin{array}{c}+ \text { coronal }_{-} \\ \text {continuant }_{\text {acoustic }} \\ - \text { distributed }_{- \text {voice }}\end{array}\right] /\left[\begin{array}{c}+ \text { coronal }_{+ \text {continuant }_{\text {acoustic }}} \\ - \text { distributed }^{-}\end{array}\right]-\#_{\text {pause }}$

(6) pre-pausal $s$ epenthesis

(a) $\varnothing \rightarrow \mathrm{s} /\{\mathrm{n} 1 \mathrm{l}\}_{-} \#_{\text {pause }}$

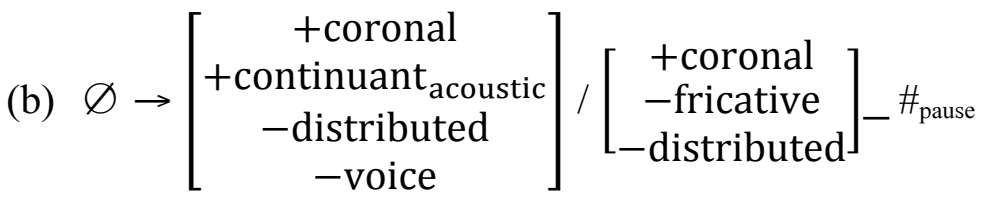

(7) phrase-internal $t$ epenthesis

(a) $\varnothing \rightarrow \mathrm{t} /\{\mathrm{n} * 1 \mathrm{~s}\}_{-} \#\left\{\mathrm{~V},{ }^{\circ} \mathrm{r}, \mathrm{j}\right\}$

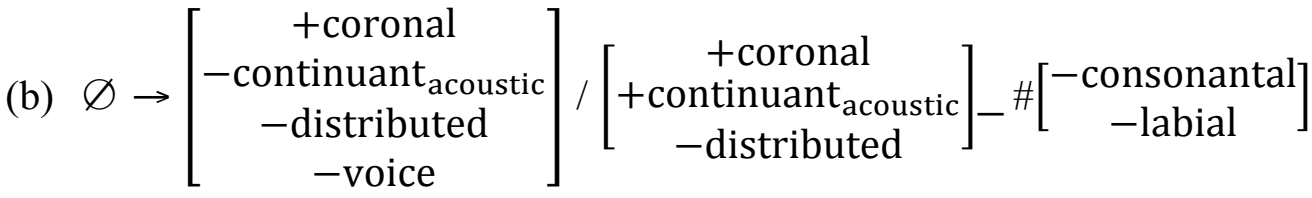

(8) phrase-internal $s$ epenthesis

(a) $\varnothing \rightarrow \mathrm{s} /\left\{\mathrm{n} 1 *^{\mathrm{t}}\right\}_{-} \#\left\{\mathrm{~V},{ }^{\mathrm{\rho}} \mathrm{r}, \mathrm{j}\right\}$

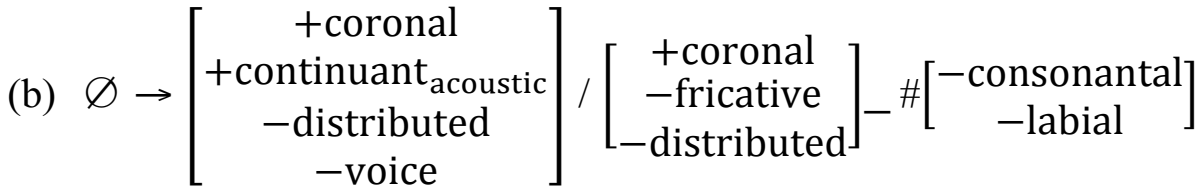

The feature [-distributed] in these rules is needed to exclude post-alveolars $\left[\begin{array}{llll}\int & t & \mathbb{6} & \mathrm{G}\end{array}\right]$. Alternatively, we can use a place specification [+alveolar]. The asterisk in the left-side environment of the phrase-internal rules (7) and (8) marks triggers which are absent in my data but whose absence is likely to be accidental. The feature [-labial] in the phrase-internal rules (7) and (8) is added to exclude [w], whose absence as the right-side environment in my data is unlikely to be accidental because I expect it to have a negative effect on the perception of any epenthetic stop or fricative that happens to be produced or perceived there (as described in section 6) as homorganic to the preceding coronal consonant.

The frequency of hypercorrection as misguided attempts to emulate a more prestigious language variety is expected to increase in more formal situations of use (cf. Labov 1966), where speakers feeling the need to speak more carefully may become more uncertain and thus overshoot 
more frequently. However, as I mentioned earlier in this section, this is the opposite of what happens. ${ }^{12}$ Furthermore, recall that the deletion of a word-final post-coronal $[\mathrm{s}]$ is not so common which argues against a simple hypercorrection analysis of the $S$ epenthesis. Thus, as mentioned in section 3, clusters involving homorganic nasals or laterals and fricatives, as in else or fence normally remain intact. Finally, the fact that the epenthesis is most common before pause while the presence or absence of a pause is largely irrelevant for the simplification of the relevant etymological word-final consonant clusters also points against the synchronic hypercorrection analysis.

\section{THE ROLE OF HYPERCORRECTION IN THE EMERGENCE OF THE $t$ AND $s$ EPENTHESIS IN BE}

As I have argued in section 5, from the synchronic perspective, it is inadequate to analyse the word-final post-coronal $t$ and $s$ epenthesis in BE as a type of hypercorrection. At the same time, as I pointed out in section 1, it is clear that some kind of compensatory behaviour for the BE tendency for word-final consonant cluster simplification, which we may refer to as hypercorrection, must have played a role in the development of the word-final post-coronal $t$ and $s$ epenthesis in BE. The tendency for word-final consonant cluster simplification is itself likely related to the absence of word-final consonant clusters in Bena L1. Furthermore, comparative evidence from other varieties of English with word-final consonant epenthesis also points to hypercorrection as the major force driving the development of such epenthesis. The high type frequency of word-final clusters with a final coronal stop as the original phonotactic pattern of English further strengthened by the constraint on voicing of final stops in BE (and several other English varieties) also explains the preference for $[\mathrm{t}]$ as the epenthetic consonant.

However, an unconstrained phonological hypercorrection scenario has some trouble explaining the $s$ epenthesis, since the deletion of a word-final post-coronal [s] is not so common in $\mathrm{BE}$ (see section 3). Another potentially problematic issue for a simple phonological hypercorrection scenario is the fact that $t$ and $s$ epenthesis in BE is found exclusively (in my dataset) after alveolar coronals, while there does not seem to be such a constraint in other English varieties with a word-final $t$ epenthesis. Even more troubling is the fact that $t$ and $s$ epenthesis occurs mostly before pause, while the presence or absence of a pause is largely irrelevant for the word-final cluster simplification in BE. Finally, a simple phonological hypercorrection scenario

\footnotetext{
${ }^{12}$ A similar argument and conclusion has been made by Childs \& Wolfram (2008: 249-250) with respect to the phonological status of the initial $h$ insertion in Bahamian English, where it co-exists with the much more frequent initial $h$ dropping and thus may seem like a type of hypercorrection.
} 
cannot explain why a productive $t$ and $s$ epenthesis is present in BE but absent in the three major varieties of Nigerian English (viz. Yoruba, Igbo and Hausa NE) and Nigerian Pidgin English, which are better studied, even though they have an equally strong tendency for word-final consonant cluster simplification.

To better account for the emergence of the $s$ epenthesis in BE, we need to enrich the phonological hypercorrection scenario by acknowledging the possibility that morphological hypercorrection has also played a role in the development of the BE pattern. Thus, in BE the nominal morpheme $-s$ and especially the verbal inflectional morpheme $-s$ are often lacking even when phonotactically they would be rather uncontroversial, for instance after a vowel, as the third singular present suffix $-s$ in (2d), while the clusters where the etymological word-final $[\mathrm{s}]$ is lexical often remain intact. The frequent omission of the past marker -ed of the weak verbs might have similarly contributed to the development of the $t$ epenthesis but its role would have obviously been much less crucial. Note that on its own a morphological hypercorrection scenario is largely insufficient, since $t$ and $s$ epenthesis shows no particular part of speech constraints and the relevant verbal and nominal morphemes may be also lacking even when their appearance would not have created a word-final cluster.

To account for the other issues that a hypercorrection analysis raises, I argue that we need to call on phonetic properties of Bena L1 such as pre-pausal glottalisation and lengthening of consonants. As described in sections 3 and 4, the pre-pausal glottalisation is realised either as (for all consonants) a glottal closure with an audible release or (for nasals and [1] only) as a fall in the intensity of the sound. The pre-pausal lengthening of consonants, which at least for stops is also correlated with the presence of glottalisation, suggests a sustained articulatory effort in the realization of consonants. The particular relevance of these phonetic properties of Bena L1 is due to their impact on the quality of approximation in $\mathrm{BE}$ of the durational and release properties of coronal consonants of more standard varieties of NE.

The hypercorrection scenario needs to be elaborated somewhat differently for $t$ and $s$ epenthesis in different contexts. However, all the scenarios share the assumption that pre-pausal glottalisation and consonant lengthening are occasionally transferred from Bena into BE. What may happen then is that a correction for the shorter audible duration of pre-pausal consonants of NE (as compared to those of Bena) is attempted at the same time, as suggested by the observation that on the whole, the final consonants in $\mathrm{BE}$ approximate the durational properties of those of $\mathrm{NE}$ relatively well. I hypothesise that such a correction is achieved primarily by compressing the glottalisation over the final part of the consonant. 
The subsequent steps for $t$ and $s$ epenthesis in different contexts are, I argue, as follows. In the scenario for the emergence of pre-pausal $t$ epenthesis after the coronal [s], [n] and [1], the transferred glottal closure is released too quickly, while the oral articulation of the preceding coronal is still largely sustained, which may occasionally result in a percept of an audibly released $[\mathrm{t}] .{ }^{13}$ Against the background of the tendency for phonological hypercorrection, the latter has good chances to become phonologised as an optional realization of a given word. The tendency for phonological hypercorrection may be expected to induce a positive bias in the perception of such glottalised coronals as being followed by an audibly released [t]. As a result, the occasional percepts of this emergent pre-pausal [t] and the occasional cases of final [t] due to phonological hypercorrection can concur for a set of speakers to bring about the reanalysis of the pre-pausal $[\mathrm{t}]$ epenthesis as being due to an optional phonological rule. In the scenario for the emergence of the pre-pausal $s$ epenthesis after [t], the transferred glottal closure is released just a moment after the oral closure sounding as a weak ejective and which may occasionally result in a percept of a sibilant following $[\mathrm{t}]^{14}$ that later became phonologised as an optional realization of a given word. Besides the ejective source, occasional pre-pausal affricated realisations $\left[\mathrm{t}^{\mathrm{s}}\right]$ mentioned in section 3 may also contribute to the emergence of a percept of a sibilant following pre-pausal $[t]$. In the scenario for the emergence of the pre-pausal $s$ epenthesis after coronals, the transferred glottal closure is occasionally undershoot when compressed over the final part of the coronal. In combination with the sustained articulatory effort in the production of the coronal, this may result in a creaky or largely devoiced period in the final part of the coronal, as in [11] or [11]. This final devoiced or non-modally voiced part of the coronal may in turn be perceived as a period of friction in the coronal area and ultimately equated with the voiceless coronal fricative [s]. The phonologisation of this optional epenthetic [s] as being due to an optional phonological rule has occurred against the background of the tendency for the morphological hypercorrection. Finally, in the case of the phrase-internal word-final post-coronal $t$ and $s$ epenthesis, two scenarios are conceivable. Given that the few examples of such epenthesis that I recorded occur before a vowel or an approximant and that in Bena L1 utterance-initial prevocalic glottalisation may be preserved in phrase-internal position in careful speech style, the first scenario would invoke glottalisation as in the scenarios outlined above for the pre-pausal contexts but the glottalisation would come

\footnotetext{
${ }^{13}$ A quick and rough demonstration of the possibility of such a percept can be obtained by inserting short silence periods in recordings of the final parts of pre-pausal [s], [n] or [1].

${ }^{14}$ As an anecdotal piece of evidence for the plausibility of such a misperception consider the observation by David Crosbie (2012) that "a Russian teacher of English heard [his] emphatic [i.e., ejective]" pronunciation of but before a pause "as an allophone of $/ \mathrm{ts} /$ ".
} 
from the word-initial vowel that follows. Alternatively, the phrase-internal epenthesis may be subsidiary to the phonologisation of the word-final epenthetic consonants in the pre-pausal context. The fact that the phrase-internal epenthesis is much less frequent than the pre-pausal epenthesis fits both scenarios. However, the fact that the phrase-internal epenthesis was found only before a vowel or an approximant is accounted for in a much more straightforward way by the first scenario.

The account involving a transfer of pre-pausal glottalisation and consonant lengthening from Bena L1 has several advantages over an unconstrained phonological hypercorrection scenario. Thus, it allows us to explain why the epenthesis in BE is largely pre-pausal, while the presence or absence of a pause is largely irrelevant for the word-final cluster simplification in BE. As outlined in the scenarios above, the transfer of pre-pausal glottalisation and consonant lengthening creates favourable conditions for the production of what may be perceived as a homorganic coronal stop or fricative, and which would thus be ripe for reanalysis as due to a phonological rule. Furthermore, it also contributes to the explanation of the fact that $t$ and $S$ epenthesis is found exclusively after alveolar coronals, as only in this environment can we end up with a percept of an existing BE stop or fricative. ${ }^{15}$ For instance, when accompanied by an audible release, the pre-pausal glottalisation of a final velar stop cannot produce a percept of any existing BE consonant, as at this place of articulation there are no other consonants available in BE (cf. table 2). Equally, when the pre-pausal glottalisation of a final bilabial nasal is accompanied by an audible release, the latter is always nasal, which cannot result in a percept of any existing BE consonant. Finally, at the post-alveolar place of articulation no stops are available in BE, only fricatives and affricates.

In addition, the account involving a transfer of pre-pausal glottalisation and consonant lengthening from Bena L1 has the potential to explain the apparent absence of a productive $t$ and $s$ epenthesis in the three major varieties of Nigerian English, viz. Yoruba, Igbo and Hausa NE, and Nigerian Pidgin English. This absence is remarkable because the tendency for word-final consonant cluster simplification in these varieties of NE and Nigerian Pidgin English is at least

\footnotetext{
${ }^{15}$ Obviously, we cannot appeal to the transfer of pre-pausal glottalisation and consonant lengthening for the potential exception mentioned in section 5.2, where $t$ epenthesis was reported after [f] before pause. Should they later prove to be possible, their emergence would have different reasons, and in fact, it is not completely unexpected (see section 7.2). However, from the standpoint of the hypothesis I advance here, they are indeed expected to be rare in BE. Not only do etymological -ft clusters tend to be preserved in $\mathrm{BE}$, but also if the transfer of the relevant phonetic properties of Bena into BE occurs, it would not result in a percept of an existing BE stop or fricative after a pre-pausal [f].
} 
as strong as that of BE. Of the three respective L1s, Hausa resembles Bena the most in its phonological structure. However, it differs from Bena in at least two important aspects. First, "words in the indigenous Hausa vocabulary all end in a vowel [...] with minor exceptions", such as "ideophones and a few apocopated or clipped forms", and while [n] and [r] occur "word finally in their function as gender-sensitive articles [...] word-final obstruents [are] prohibited" (in the native Hausa vocabulary) (Newman 2000: 317, 319). It is English that is responsible for "introducing large numbers of words with final consonants" into Hausa. Second, although Hausa like Bena has pre-pausal glottalisation, in Hausa it is confined to pre-pausal vowels, and except when the vowel is phonologically short, its appearance is conditioned lexically (cf. Ma Newman $\&$ van Heuven 1981). Finally, word-final consonant lengthening has not been reported for Hausa either. Yoruba and Igbo L1 lack both word-final consonants and pre-pausal glottalisation. Given that the possibility of word-final consonants in the native L1 lexicon, pre-pausal glottalisation and consonant lengthening can be argued to create favourable conditions for the production of what may be perceived as, and subsequently phonologised as, a homorganic coronal stop or fricative in L2 English, the lack of these features in Hausa, Yoruba and Igbo may explain why the available potential for phonological hypercorrection has not developed into a productive word-final $t$ and $s$ epenthesis in the respective L2 Englishes.

Finally, the comparison of the more standard varieties of NE and Nigerian Pidgin English with $\mathrm{BE}$ arguably suggests that the $t$ and $s$ epenthesis in $\mathrm{BE}$ emerged during the period when more British-like pronunciation of English, in particular as regards the faithful reproduction of wordfinal consonant clusters, was prestigious in Nigeria, that is during or early after the colonial period. Thus, as I have noted above, in more formal situations of English use, BE speakers appear to approximate the pronunciation of more standard varieties of $\mathrm{NE}$ in terms of cluster simplification tendencies in reducing both the frequency of the $t$ and $s$ epenthesis and of correct productions of etymological word-final clusters with $t$ and $s$. This makes it unlikely that the more standard varieties of $\mathrm{NE}$ in their current form served as the trigger for the development of the hypercorrection process that originally contributed to the emergence of the epenthesis in BE. Therefore, the hypercorrection must have been primarily triggered by contact with a more Britishlike pronunciation at the time when it enjoyed more prestige in Nigeria, since nowadays Britishlike pronunciation "does not have a high social prestige in Nigeria and is ridiculed as affected and arrogant" (Gut 2008: 39). In addition, it is not inconceivable that in the absence of direct contact with British-like pronunciation, the familiarity with written English at school has been contributing to the development of the hypercorrection. 


\section{WORD-FINAL CONSONANT EPENTHESIS IN OTHER VARIETIES OF ENGLISH}

Besides BE, cases of word-final consonant epenthesis have been reported for a number of New Englishes as well as for several of the so-called Inner Circle Englishes. Before proceeding further, note that I will not consider cases such as the development of excrescent final $-t$ in a set of English prepositions and adverbs originally formed by means of the genitive $-s$, such as against, amidst, amongst, etc. Neither will I consider the few other sporadic examples of "the addition of nonetymological <-t > " in the history of English cited by Minkova (2014:150), such as behest, hoist and tuft, which do not form any kind of coherent group at all. According to the OED online (2014), the likely source of the excrescent final $-t$ in against was its frequent collocation with a subsequent te, variant of the, perhaps reinforced by association with superlatives in -st. Unlike the word-final post-coronal $t$ and $s$ epenthesis in BE, this excrescent final $-t$ in the history of English is confined to a limited number of words of a certain morphosyntactic class and morphological structure. Furthermore, it has developed phrase-internally, whereas the BE pattern has developed pre-pausally.

\subsection{Word-final consonant epenthesis in New Englishes}

Holm (1988: 142) provides an isolated example of a word-final epenthetic [t], viz. cinnamon[t], in Miskito Coast Creole English spoken in Central America and considers it to be hypercorrection. No information is provided on the productivity of the epenthesis.

A productive word-final consonant epenthesis has been reported for a number of New Englishes in Southeast Asia, such as Singapore English, Hong Kong English (Setter \& Deterding 2003), and Brunei English (Deterding \& Sharbawi 2013: 29). For Brunei English, Deterding \& Sharbawi (2013: 29) note only the use of epenthetic word-final [t]. In the examples of epenthesis they provide, [t] is always added after a word-final [n] before pause. Deterding \& Sharbawi (2013: 29) concede that "it is hard to be certain what the origin of this extra $[t]$ is", but hypothesize that "it may be a spurious -ed suffix". Setter \& Deterding's (2003) description of the word-final consonant epenthesis in Singapore English (SE) and Hong Kong English (HE) provides the largest number of examples and suggests that the epenthesis is productive. The epenthetic consonants involved are mostly [t] and in a few cases $[\mathrm{s}] .{ }^{16}$ The consonants after which an epenthetic [t] appears in the examples are coronals, mostly $[\mathrm{n}](9,10)$ and $[\mathrm{s}](11)$, and in one case [1] (12).

\footnotetext{
${ }^{16}$ They also mention one example which they consider as epenthesis of [k], viz. so it's fun being $[\mathrm{k}]$ with them. However, this rather seems to be a case of a pronunciation influenced by spelling or possibly a failure to produce [y] correctly, as is typical for instance for many European L2 English varieties.
} 
There is also one suspicious example where [t] is said to appear after [y] (13). In the case of the epenthetic [s], the preceding consonant is [t], as in (14). Furthermore, unlike in BE, an epenthetic [t] and [s] may also appear after a word-final vowel, as in (15) and (16). The epenthesis is typically pre-pausal, as in $(9,11,13,14,16)$ and presumably $(15)$, but as compared to $\mathrm{BE}$, the proportion of cases of phrase-internal epenthesis, as in $(10,11)$, is relatively high and any clear restrictions on the phonological context to the right of the word in question in the case of the phrase-internal epenthesis appear to be lacking.

(9) yah the trekking is ... was fun $[\mathrm{t}](\mathrm{SE})^{17}$

(10) so it's fun $[\mathrm{t}]$ being with them (SE)

(11) and renovate my house[t] (SE)

(12) I think you may be doubtfuI $[\mathrm{t}]$ about the reason (HE)

(13) cycling, hiking, um sailing[t], and some kayaking (HE)

(14) the last night out $[\mathrm{s}]$... er on the way back (SE)

(15) er yah, to me[t] I feel that the knowledge would help (SE)

(16) but for today[s], I think I can only show you ... (HE)

Setter \& Deterding (2003) hypothesise that at least "the instances of an extra $/ \mathrm{t} /$ after final $/ \mathrm{n} /$ " may have an "articulatory explanation" with the velum being raised too early before the release of the alveolar closure. Alternatively, they suggest that "the extra /t/ [...] is a spurious -ed suffix" and "the extra /s/ can be regarded as spurious $-s$ suffixes", both "introduced as a kind of [morphological] hypercorrection".

The word-final consonant epenthesis in SE and HE resembles that in BE in terms of the word-final and epenthetic consonants involved, in terms of productivity and in terms of the preferred phonological context to the right of the word in question, viz. before pause. The two major differences are that in SE and HE, the epenthesis also occurs after word-final vowels and that the phrase-internal epenthesis is not constrained by the phonological context to the right of the word in question and appears to occur at a considerably higher rate. Both the similarities and differences are quite revealing in that they square well with the similarities and differences in the phonologies of the respective L1s and in the sociolinguistic patterns of L1 and L2 relations. For HE, L1 is Cantonese, a Yue Sinitic language. For SE, although there are a number of L1s involved, the primary contributors are Sinitic languages from the southeastern coast of China,

${ }^{17}$ Examples (9) to (16) are reproduced from Setter \& Deterding (2003: 1876). 
especially Min Nan varieties, such as Hokkien, Teochew and Hainanese, and Yue varieties, such as Cantonese. More recently, Mandarin Chinese has also been gaining substantial ground in both Hong Kong and Singapore. The word-final consonant phonologies of the southeastern Sinitic languages are sufficiently similar to each other and are characterized by the lack of consonant clusters and the possibility of word-final nasal [m, n, $\mathrm{y}]$ and oral stops [p, t, k], but no [s] and [1].

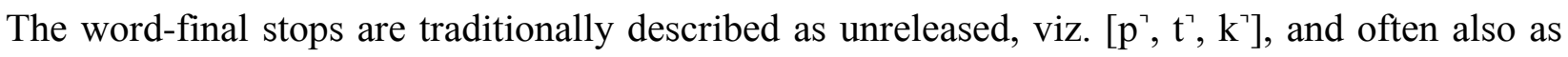

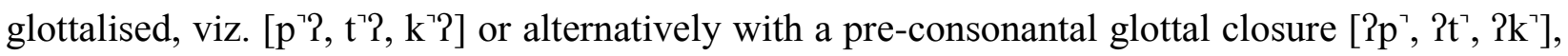
(see for instance Iwata et al. 1981, Cheung 1986 for Cantonese). I do not know whether the wordfinal nasals can also be glottalised. The glottal stop sometimes completely obscures the presence of the oral closure and this process is generally assumed to be responsible for the tendency for the reduction of the consonant inventories at the ends of words, and more generally, syllables in Southeast Asian languages. Although as in some other Southeast Asian languages the details of the glottalisation of word-final consonants may be more complex (cf. Michaud 2004), the important difference with Bena is that the glottalisation here is more a feature of consonants at the end of words or just syllables than a feature of consonants before pause, even though it is likely to be more frequent before pause. The masking and subsequent loss of the oral closure of word-final consonants observed in the relevant Sinitic languages are also primarily conditioned by their position in the word or syllable rather than by the presence of a pause after them. These peculiarities in the realisation of word-final consonants clearly have an important bearing on the higher rate of phrase-internal word-final consonant epenthesis in SE and $\mathrm{HE}$ as compared to $\mathrm{BE}$ and on the fact that unlike in BE, consonant epenthesis is also possible after word-final vowels in SE and HE. In this respect, consider also the observation by Cruz-Ferreira (2005: 31-32) that SE is characterized by "a more general avoidance of alveolar stops in codas, including the nasal", also after vowels, as in (17-19).

(17) My older niece is about [ə'bav] five... this year... (SE)

(18) And then before that is the Practicum, which I did [di] in Ghim Moh Primary School(SE)

(19) some ... design [dı'zar] some clothes (SE)

Interestingly, Cruz-Ferreira (2005: 32) notes that this coda omission process "does not seem to affect alveolar fricatives", such as [s]. However, I am strongly inclined to believe that the [s] omission is just less common rather than plainly absent, given that it is attested in other Southeast Asian L2 varieties of English whose L1s have similar word-final consonant phonologies, as in Thai L1 English pronunciations such as [lai] for rice. The apparent lower frequency of the 
omission of word-final [s] suggested by the observation made by Cruz-Ferreira (2005) does square well, though, with the lower frequency of the word-final $s$ epenthesis in comparison with the word-final $t$ epenthesis in SE and HE. The findings by Cruz-Ferreira (2005) also suggest that the primary driving force behind the emergence of the $t$ and $s$ epenthesis in SE and (by extension also) HE is phonological rather than morphological hypercorrection. Furthermore, given that the epenthesis is productive and the British or American-like pronunciation with a more faithful realisation of word-final consonants enjoys a sufficiently high prestige for speakers of SE and $\mathrm{HE}$, there are much more grounds, in comparison to $\mathrm{BE}$, to conceive the $t$ and $s$ epenthesis in $\mathrm{SE}$ and HE in terms of still being a synchronic hypercorrection process. Finally, the role of glottalisation of word-final consonants in the emergence of the $t$ and $s$ epenthesis in SE and HE is different from what I argued for BE in section 6. Whereas in BE the glottalisation of wordfinal consonants arguably creates favourable conditions for the production of what may be perceived, and subsequently phonologised, as a homorganic coronal stop or fricative, in SE and $\mathrm{HE}$ its primary contribution is that it occasionally masks and then replaces the oral closure, thus creating favourable conditions for the emergence of phonological hypercorrection.

\subsection{Word-final consonant epenthesis in Inner Circle Englishes}

Word-final post-consonantal $t$ epenthesis has been reported for at least two of the so-called Inner Circle Englishes, viz. older Southern rural white American English (Thomas 2008: 110), SrwAE, ${ }^{18}$ and Newfoundland English (Clarke 2008: 175), NfE. The epenthesis does not seem to be productive in either variety, as both sources describe it as occurring in "a few" or "handful" words. Thus, according to Thomas (2008: 110), in SrwAE, "[a] few words, notably once, twice, across, and cliff, may show an intrusive [t] after the final fricative", although "intrusive [t] is also reported in other words, e.g., sermont for sermon". Similarly, according to Clarke (2008: 175), in NfE, "[i]n a handful [of words] /t/ may be added, as in cliff pronounced [klift] and skiff, [skift]". The apparent fact that the epenthesis is lexically conditioned suggests that in either variety, it is not appropriate to treat it as a case of synchronic hypercorrection or as a case of a synchronic phonological rule, as in BE. Furthermore, the description of the epenthesis in lexical terms in both sources suggests that the presence of a pause in the phonological context immediately to the right of the word in question has no relevance for the application of epenthesis

\footnotetext{
${ }^{18}$ According to Thomas (2008: 110), the process may in fact have a wider geographic and sociolinguistic distribution, as it is "not limited to the South but is especially common in older rural Southern white speech".
} 
in SrwAE and NfE, unlike in BE, but more like in SE and HE. At the same time, unlike in SE and HE, $t$ epenthesis occurs only after word-final consonants, not vowels, thus creating nonetymological consonant clusters. The latter restriction is clearly related to the fact that in both SrwAE and NfE, word-final etymological consonants are deleted only when they are part of consonant clusters. ${ }^{19}$ Finally, SrwAE and NfE differ from the three New Englishes with $t$ epenthesis in that the word-final consonant in the left context of the epenthesis is not necessarily coronal. Thus, Thomas (2008) describes the word-final consonant in the left context as fricative, viz. the coronal sibilant [s] and the labiodental non-sibilant [f], and occasionally [n]. Clarke (2008) provides only examples with the labiodental fricative [f].

As in the three New Englishes, the $t$ epenthesis in SrwAE and NfE likely has its origin in phonological hypercorrection, as suggested by the following facts. First, both varieties are known for their extensive word-final consonant cluster simplification largely irrespective of the phonological context to the right of the word in question. Second, already for some time, both varieties have become involved in more intense contact with some more prestigious English varieties where the simplification of word-final consonant clusters is much less radical. Although the rate of simplification in the two varieties appears to be still higher than in many other varieties of English, the general pattern of the simplification has become largely similar to that of these more prestigious varieties. Thus, the "unusually high rate of consonant cluster simplification" is known to be the "traditional" feature of Southern American English that has "largely disappeared from urban" Southern American English (Tillery \& Bailey 2008: 125), and even in SrwAE the pattern of simplification is "as with other varieties of English" (cf. Thomas 2008: 110). Similarly, in NfE, the exceptionally high rate of word-final consonant cluster simplification, particularly the final "/t/ and /d/ deletion" after "a homorganic obstruent, nasal or liquid", is characteristic of "vernacular" NfE, and in the unusual context before a vowel, it is common only with "oldfashioned or 'deep' vernacular speakers" (Clarke 2008: 175). The few lexically conditioned cases of $t$ epenthesis reported for SrwAE and NfE can thus be considered as remnants of the stage when the growing influence of the other, more prestigious varieties of English with a less radical wordfinal consonant cluster simplification pattern has triggered $t$ epenthesis as productive phonological hypercorrection. As this staged passed, the epenthesis has lost its productivity.

That the left context for $t$ epenthesis in SrwAE and NfE is not restricted to coronals need not require an explanation as such. This is actually to be expected, if the epenthesis in these

\footnotetext{
${ }^{19}$ With the exception of a few monosyllabic unstressed words in NfE, such as with, of, give, where "single consonants in syllable-coda position are also subject to deletion" (Clarke 2008: 175).
} 
varieties has a purely phonological hypercorrection origin, since word-final consonant clusters in the more prestigious varieties that have triggered the development of hypercorrection include also lexical clusters of word-final [t] or [d] preceded by a non-coronal. At the same time, what does require an explanation is why the inserted consonant is [t], why the left context of the epenthesis does not include the oral coronal sonorant [1], the post-alveolar fricative [S], and other non-coronal obstruents, as well as why the epenthesis is more common (or perhaps, only possible) in certain words but not the others that otherwise have the same word-final consonant. For some of these questions, I presume the explanation has to do with differences in frequency (type and/or token) of particular kinds of word-final consonant clusters in the relevant non-simplifying varieties. Thus, this is very likely the reason why the inserted consonant is [t] and the left context of the epenthesis does not include the post-alveolar fricative [ $\left.\int\right]$ and non-coronal stops and nasals, but does include the non-sibilant labiodental fricative [f]. Another factor favouring [t] as the inserted consonant is likely to be related to the fact that among the possible word-final stops [t], together with its voiced counterpart [d], is the one most liable to deletion in English (e.g., see Tagliamonte $\&$ Temple 2005 for a recent discussion of “- $t$, $-d$ deletion" and many references to earlier studies). The reason that [1] is not mentioned as the left context for the $t$ epenthesis is probably due to the fact that in both SrwAE and NfE, as in many other varieties of North American English, syllablecoda [1] is typically vocalised and it is sometimes also deleted as the first element of an etymological word-final consonant cluster (cf. Clarke 2008: 174, Thomas 2008: 107). That is, since the etymological [1] is vocalised or deleted, it cannot serve as a context for $t$ epenthesis anymore. As to the apparent lexical differences in the application of $t$ epenthesis, it is again frequency effects that may have played an important role. Furthermore, the possibility of $t$ epenthesis in words such as once, twice, across in SrwAE may have something to do with analogy with the forms, such as against, amidst, and amongst, mentioned in the beginning of section 7. Thus, these words are relatively common in the same environment that triggered the emergence of the excrescent final $-t$ in against, amidst, and amongst. They also share the morphological structure with the latter group to a certain extent, and at least in the case of across, also the morphosyntactic class.

\section{CONCLUSION}

I have presented a description of an interesting case of word-final consonant epenthesis from North-eastern NE of speakers whose L1 is the Adamawa language Bena (ISO 639-3: yun). BE is not the only variety of English for which some kind of word-final consonant epenthesis has been reported in the literature. Unlike the varieties for which no such epenthesis has been reported, all 
these varieties appear to have extensive word-final consonant cluster simplification largely irrespective of the phonological context to the right of the word in question. The combination of their relatively low social prestige as compared to the other varieties which both have significantly lower rates of word-final cluster simplification and lack such epenthesis, suggests hypercorrection of the tendency for word-final consonant cluster simplification as an obvious explanation. Similarly, a strong preference for $[\mathrm{t}]$ as epenthetic consonant in all these varieties points towards hypercorrection as a strategy to resolve the mismatch between the high frequency of word-final clusters with a final coronal stop in the relevant prestige varieties and the simplified word-final phonotactic pattern of the varieties such as BE.

In addition to a synchronic description of the word-final consonant epenthesis in $\mathrm{BE}$, I have also explored the mechanisms that must have been active in the emergence of this phenomenon in BE as compared to other English varieties where some kind of word-final consonant epenthesis is also attested. It is clear that hypercorrection must have played an important role in the emergence of the epenthesis in all varieties. However, I argued that a simple hypercorrection analysis falls short of answering many of the why and how questions with respect to the details of epenthesis in different varieties. Furthermore, at least in the case of BE, and probably also for SrwAE and NfE, from the synchronic point of view, the analysis of the pattern as hypercorrection is no more adequate, which implies that even though BE speakers are L2 speakers, the reinterpretation has taken place on a speech-community level and is not just a language-learning phenomenon. In the case of $\mathrm{BE}$, the latter generalisation is indirectly supported by the fact that the current prestige varieties relevant for BE, viz. the more standard varieties of NE (and possibly Nigerian Pidgin English), can hardly serve as a trigger for epenthesis as hypercorrection, since they are characterized by a tendency for extensive word-final consonant cluster simplification very much comparable to that of BE itself. As to the hypercorrection analysis of the emergence of the BE pattern, I argued that it needs to be elaborated in several respects. First, I argue that morphological hypercorrection may have also contributed to the development of the $s$ epenthesis. Second, a more plausible account of both the actuation of the hypercorrection and the phonologisation of the epenthesis in BE can be achieved by calling on phonetic properties of Bena L1 such as pre-pausal glottalisation and lengthening of consonants. Thus, this allows us to explain why the epenthesis in BE is largely pre-pausal, while the presence or absence of a pause is largely irrelevant for the word-final cluster simplification in BE. In addition, it contributes to the explanation of the fact that $t$ and $s$ epenthesis is found after coronals, as we can only end up with a percept of an existing BE stop or fricative in such an environment. In sum, the phonologisation of the word-final consonant epenthesis in $\mathrm{BE}$ is a result of a diachronic reanalysis 
driven by the concurrence of hypercorrection of the extensive word-final consonant cluster simplification tendency in BE as L2 and pre-pausal glottalisation and lengthening of consonants in Bena as L1. The reanalysis was done by one generation of learners who assumed the consonants that were occasionally perceivable due to these factors were instead due to an optional rule of $t$ and $S$ excrescence contingent on a preceding [+ coronal, -distributed] specification. The epenthesis rule could emerge diachronically in BE only because the speakers of BE happened to have this constellation of factors. Aspects of the origins of the epenthesis as a pre-pausal phenomenon are echoed in the pre-pausal tendency in the application of this optional rule.

The analysis of the epenthesis in BE advanced in the paper has contributed to a better understanding of the details of word-final consonant epenthesis in other English varieties. Like the BE epenthesis pattern, the epenthesis pattern in the Southeast Asian New Englishes discussed in section 7.1 can be largely accounted for by the phonological and phonetic properties of their respective L1s, just as the differences and similarities between the BE pattern and the Southeast Asian pattern. The word-final consonant epenthesis pattern in the two Inner Circle Englishes, viz. SrwAE and NfE, shows some significant differences from the patterns found in the New Englishes in terms of both its productivity and conditioning. I believe this is primarily related to the fact that the original phonological and phonetic properties of SrwAE and NfE were more in line with those of the relevant prestige varieties of English than in the case of the L1s of the New Englishes under consideration. The difference in productivity of epenthesis between the Inner Circle Englishes and the New Englishes can be explained by differences in the respective sociolinguistic contexts. Thus, the two Inner Circle Englishes have long been in a much more intense interaction with the more prestigious English varieties where simplification of word-final consonant clusters is much less radical.

As argued in section 6, the optional rule of word-final $t$ and $s$ epenthesis in BE can be offered a clear phonetic explanation. Thus, it is contingent on a preceding $[+$ coronal, distributed] specification, and diachronically, also on the pre-pausal prosody of glottalisation and lengthening of the word-final consonant. The availability of such a phonetic explanation makes this sound pattern conceivable as a natural rule. Combined with the fact that pre-pausal glottalisation and lengthening prosody is relatively common cross-linguistically, we might expect such a sound pattern to arise occasionally in the languages of the world through regular sound change. Yet, such types of epenthesis are unattested in non-contact lects. The typological rarity 
of this epenthesis in non-contact lects highlights once more the positive bias induced by hypercorrection as a necessary part of the mix in creating the conditions for a reanalysis. ${ }^{20}$

${ }^{20}$ The emergence of some other types of epenthesis in the languages of the world may also prove to be restricted to contact lects. This has been argued by Juliette Blevins (ms.) for cluster-splitting vowelepenthesis \#TRV $\rightarrow$ $\rightarrow T^{T} V_{(i)} R V_{i}$ (where $T$ is an oral stop and $R$ a liquid). Although seemingly natural, it is extremely rare as a regular sound change, and in fact is "not known as a purely language-internal development". 
Author's address:

LLACAN (UMR $8135 d u$ CNRS)

7, rue Guy Môquet - BP 8

94801 Villejuif Cedex

France

E-mail:dmitry.idiatov@cnrs.fr 


\section{ABBREVIATIONS}

BE - Bena English

HE - Hong Kong English

NE - Nigerian English

$\mathrm{NfE}$ - Newfoundland English

SrwAE - Southern rural white American English

SE - Singapore English

\section{REFERENCES}

Blevins, Juliette. 2007. Consonant epenthesis: natural and unnatural histories. In Good, Jeff (ed.) Language universals and language change. Oxford: OUP, 79-107.

Blevins, Juliette. ms. Between natural and unnatural phonology: the case of cluster-splitting epenthesis.

Broselow, Ellen. 1984. Default consonants in Amharic morphology. In Margaret Speas \& Richard W. Sproat (eds.), Papers from the January 1984 MIT Workshop in Morphology, 15-32. Cambridge: Department of Linguistics and Philosophy, MIT.

Buizza, Emanuela \& Leendert Plug. 2012. Lenition, fortition and the status of plosive affrication: the case of spontaneous RP English /t/. Phonology 29(1), 1-38.

Cheung, Kwan Hin. 1986. The phonology of present day Cantonese. Ph.D. dissertation, University College London.

Childs, Becky \& Walt Wolfram. 2008. Bahamian English: phonology. In Edgar W. Schneider (ed.), Varieties of English 2: The Americas and the Carribean, 239-255. Berlin: Mouton de Gruyter.

Clarke, Sandra. 2008. Newfoundland English: phonology. In Edgar W. Schneider (ed.), Varieties of English 2: The Americas and the Carribean, 161-180. Berlin: Mouton de Gruyter.

Crosbie, David. 2012. Comment on John Well's phonetic blog: no (audible) release. http://phonetic-blog.blogspot.be/2012/03/no-audible-

release.html? showComment $=1331726360900 \#$ c5175068805895228579 $\quad$ [accessed 6 August 2014]

Cruz-Ferreira, Madalena. 2005. Past tense suffixes and other final plosives in Singapore English. In David Deterding, Adam Brown \& Ee Ling Low (eds.), English in Singapore: phonetic research on a corpus, 26-36. Singapore \& New York: McGraw Hill. 
Deterding, David \& Salbrina Sharbawi. 2013. Brunei English: a new variety in a multilingual society. Dordrecht \& New York: Springer.

Faraclas, Nicholas G. 1996. Nigerian Pidgin. London \& New York: Routledge.

Fourakis, Marios \& Robert Port. 1986. Stop epenthesis in English. Journal of Phonetics 14, 197221.

Gut, Ulrike B. 2008. Nigerian English: phonology. In Rajend Mesthrie (ed.), Varieties of English 4 (Africa, South and Southeast Asia), 35-54. Berlin, Boston: Mouton de Gruyter.

Gut, Ulrike. 2009a. Non-native Speech: A Corpus-based Analysis of Phonological and Phonetic Properties of L2 English and German. Frankfurt am Main: Peter Lang.

Gut, Ulrike. 2009b. First language influence and final consonant clusters in the new Englishes of Singapore and Nigeria. World Englishes 26(3), 346-359.

Holm, John. 1988. Pidgins and creoles. Vol. 1: Theory and structure. Cambridge: Cambridge University Press.

Iwata, R., Sawashima, M. \& H. Hirose. 1981. Laryngeal adjustments for syllable-final stops in Cantonese. Annu. Bull. Res. Inst. Logop. Phoniat. 15, 45-54.

Labov, William. 1966 The social stratification of English in New York City. Washington: Center for Applied Linguistics.

Labov, William. 1989. The child as linguistic historian. Language Variation and Change 1, 8597.

Lee, Sook-hyang. 1991. The duration and perception of English epenthetic and underlying stops.

The Journal of the Acoustical Society of America 89(4B), 1999-1999. doi:10.1121/1.2029835.

Ma Newman, Roxana \& Vincent J. Van Heuven. 1981. An acoustic and phonological study of pre-pausal vowel length in Hausa. Journal of African Languages and Linguistics 3, 1-18.

Michaud, Alexis. 2004. Final consonants and glottalization: New perspectives from Hanoi Vietnamese. Phonetica 61(2-3), 119-146.

Minkova, Donka. 2014. A historical phonology of English. Edinburgh: Edinburgh University Press.

Morley, Rebecca L. 2012. The emergence of epenthesis: an incremental model of grammar change. Language Dynamics and Change 2, 59-97.

Newman, Paul. 2000. The Hausa language: an encyclopedic reference grammar. New Haven: Yale University Press.

OED Online. 2014. "against, prep., conj., adv., and n.”. Oxford University Press. http://www.oed.com/view/Entry/3754?redirectedFrom = against [accessed 23 June 2014] 
Ohala, John J. 1986. Consumer's guide to evidence in phonology. Phonology Yearbook 3, 3-26. Ohala, John J. 2003. Phonetics and historical phonology. In Brian D. Joseph \& Richard D. Janda (eds.), The handbook of historical linguistics, 669-686. Oxford: Blackwell Publishing.

Recasens, Daniel. 2012. The phonetic implementation of underlying and epenthetic stops in word final clusters in Valencian Catalan. Journal of the International Phonetic Association 42(1), 65-90. doi:10.1017/S0025100311000508.

Setter, Jane \& David Deterding. 2003. Extra final consonants in the English of Hong Kong and Singapore. Proceedings of the 15th International Congress of Phonetic Sciences, Barcelona, August, 1875-1878.

Simo Bobda, Augustin. 2007. Some segmental rules of Nigerian English phonology. English World-Wide 28(3), 279-310.

Tagliamonte, Sali \& Rosalind Temple. 2005. New perspectives on an ol' variable: (t,d) in British English. Language Variation and Change 17(3).

Tillery, Jan \& Guy Bailey. 2008. The urban South: phonology. In Edgar W. Schneider (ed.), Varieties of English 2: The Americas and the Carribean, 115-128. Berlin: Mouton de Gruyter.

Thomas, Erik R. 2008. Rural Southern white accents. In Edgar W. Schneider (ed.), Varieties of English 2: The Americas and the Carribean, 87-114. Berlin: Mouton de Gruyter.

Ugorji, C. U. C. 2010. Nigerian English phonology. Frankfurt am Main: Peter Lang.

Van de Velde, Mark \& Dmitry Idiatov. 2017. Morphological classes and gender in Báná-Yungur. In Shigeki Kaji (ed.), Proceedings of the 8th World Congress of African Linguistics, 5365. Tokyo: Research Institute for Languages and Cultures of Asia and Africa, Tokyo University of Foreign Studies.

Vaux, Bert. 2002. Consonant epenthesis and the problem of unnatural phonology. https://www.academia.edu/300583/Consonant_Epenthesis_and_the_Problem_of_Unnatural_P honology.

Warner, Natasha \& Andrea Weber. 2001. Perception of epenthetic stops. Journal of Phonetics 29(1), 53-87. doi:10.1006/jpho.2001.0129.

Yoo, Isaiah WonHo \& Barbara Blankenship. 2003. Duration of epenthetic [t] in polysyllabic American English words. Journal of the International Phonetic Association 33(2), 153-164. doi:10.1017/S0025100303001269.

Żygis, M. 2010. Typology of consonantal insertions. ZASPiL Nr. 52-September 2010 Papers from the Linguistics Laboratory, 111-140. 